NUMERICAL ANALYSIS AND MATHEMATICAL MODELLING

BANACH CENTER PUBLICATIONS, VOLUME 24

PWN-POLISH SCIENTIFIC PUBLISHERS

WARSAW 1990

\title{
SOME ASPECTS OF SIMULTANEOUS RATIONAL APPROXIMATION
}

\author{
MARCEL G. DE BRUIN
}

Faculty of Technical Mathematics and Informatics, Delft University of Technology, Delft, The Netherlands

This paper is the completed version of a series of lectures given during the semester. After a section on (part of) the historical developments, the attention is focused on simultaneous rational approximation with common denominator (so-called German-polynomials or type II polynomials) and the connection with recurrence relations of the Jacobi-Perron type, generalising the well-known continued fraction algorithm.

\section{History}

The roats lie in Number Theory: it was Ch. Hermite [103] who introduced two sets of polynomials in the study of approximation of a set of exponential functions, connected with the transcendency of $e$. Using the notations that are customary nowadays, the approximation problem can be formulated as follows. Let $n$ be a natural number and consider

$$
\begin{array}{ll}
f_{0}, f_{1}, \ldots, f_{n} & n+1 \text { formal power series in } z, \\
\varrho_{0}, \varrho_{1}, \ldots, \varrho_{n} \quad n+1 \text { non-negative integers, } \sigma=\varrho_{0}+\varrho_{1}+\ldots+\varrho_{n} .
\end{array}
$$

Find polynomials $P_{0}, P_{1}, \ldots, P_{n}$ in $z$, satisfying

$$
\operatorname{deg} P_{j} \leqslant \varrho_{j} \quad(0 \leqslant j \leqslant n), \quad \sum_{j=0}^{n} P_{j} f_{j}=O\left(z^{\sigma+n}\right)
$$

(so-called Latin- or type I polynomials) and an $(n+1)$-tuple satisfying

$$
\operatorname{deg} P_{j} \leqslant \sigma-\varrho_{j} \quad(0 \leqslant j \leqslant n), \quad P_{0} f_{j}-P_{j} f_{0}=O\left(z^{\sigma+1}\right) \quad(1 \leqslant j \leqslant n)
$$

(so-called German- or type II polynomials). From a simple counting argument (number of unknowns, the coefficients of the polynomials, versus the number of equations) we infer that there always exists a non-trivial solution (i.e. not all polynomials do vanish). 
For $n=1$ (here type I and type II "coincide" on taking $f_{0} \equiv 1$ ) there is an enormous list of references (only several are contained in the list at the end of this paper). The name Padé table was introduced in the beginning of the twentieth century, mainly on basis of the important pioneering work done by H. Padé [156]; he also looked into the type I case for $n \geqslant 2$ in [159].

At first not so much attention was paid to the concept outside the field of Number Theory (construct rational approximants having high order of contact at the origin with certain functions, leading to an approximation of numbers by rationals too good to satisfy the famous Thue-Siegel-Roth theorem, thereby proving irrationality or even transcendency), except for an isolated generalisation into the direction of type II for a set of Stieltjes functions by A. Angelesco [1]-[4]. In 1934 there was a thesis by a student of Perron, J. Mall [148], a reference that surfaced a few years ago (during the continuing search by Claude Brezinski for references for his Padé bibligraphy), but as far as is known now, there was no follow-up from that source.

In 1934/1935 K. Mahler (finding shelter at the University of Groningen with his friend Jan Popken) wrote a long manuscript on the algebraic approximation of functions pointing out the intimate connection between the two types of polynomials. It was in 1968 that this manuscript was finally published [147] (it was the notation from this paper that led to the names German- and Latin-polynomials); the algebraic approach was continued by J. Coates [63], A. J. Goddijn [85], H. Jager [119], J. H. Loxton and A. J. van der Poorten [137], [138], A. J. van der Poorten [170], [171].

In the mean time the physicists had "rediscovered" the Padé approximant. and its importance (cf. G. A. Baker jr. [12], who also wrote two books on the $n=1$-case with P. R. Graves-Morris (vol. 11 and 12) in the series "Encyclopedia of Mathematics" edited by G.-C. Rota). It would be outside the scope of this paper to go into more detail regarding this case of the so-called "ordinary Padé table", but there are many important contributions of which only some will be mentioned here to give the reader a point of entry into the vast literature: A. I. Aptekarev [5], R. J. Arms and A. Edrei [9], A. Edrei [82] connected with [177], Peter B. Borwein [20], C. Brezinski [23], [25], M. G. de Bruin [27], A. A. Gonchar and G. Lopez L. [86], V. A. Kalyagin [125], G. Lopez L. [132]-[136] and many others, whose contributions can be found all over the literature and the fact that they are not mentioned here, has only to do with the aim of this paper to treat simultaneous approximation and does not by any means imply anything about the relevance of their work.

After 1970 the developments did run along several lines.

Type I and type II polynomials. A. I. Aptekarev [6], [7], A. I. Aptekarev and V. A. Kalyagin [8], G. A. Baker jr. [12], G. A. Baker jr. and D. S. Lubinsky [13], Peter B. Borwein [18], [19], M. G. de Bruin [26], [28], [29], [33], [35]-[39], D. V. Chudnovsky [51], D. V. Chudnovsky and G. V. Chudnovsky [52], G. V. Chudnovsky [59]-[61], J. Della Dora [76]-[78], J. Della Dora and 
C. Di-Crescenzo [79], [80], E. M. Nikishin [151], V. N. Sorokin [186], H. Stahl [187]-[189].

Vector-valued interpolants. P. R. Graves-Morris [89], [90], P. R. GravesMorris and C. D. Jenkins [92], [93], P. R. Graves-Morris and E. B. Saff [94], P. R. Graves-Morris and J. M. Wilkins [95], J. van Iseghem [107], [108], [110], [112], D. E. Roberts and P. R. Graves-Morris [174].

Using orthogonal polynomials. M. G. de Bruin [37], S. K. Burley, S. O. John and J. Nuttall [44], G. V. Chudnovsky [62], A. A. Gonchar and E. A. Rakhmanov [87] (E. A. Rakhmanov [173]), J, van Iseghem [109], [111], A. Iserles and S. P. Nørsett [113]-[115], A. Iserles and E. B. Saff [116], J. Nuttall [153], [154], V. A. Kalyagin [124], J. Nuttall and G. M. Trojan [155], E. M. Nikishin [152], V. N. Sorokin [185].

Algebraic Hermite-Padé approximants. G. A. Baker jr. and D. S. Lubinsky [13], Peter B. Borwein [18], [19], R. E. Shafer [180], H. Stahl [187]-[189]. Differential Hermite-Padé approximants. G. A. Baker jr. and D. S. Lubinsky [13], G. S. Joyce and A. J. Guttman [122], H. Stahl [187]-[189]. The last two types mentioned construct polynomials of type I for the set of functions $1, f, f^{2}, \ldots, f^{n}$ resp. $1, f, f^{\prime}, \ldots, f^{(n)}$. In the order condition $(0)$ on the previous page the functions are replaced by $y^{j}$ resp. $y^{(j)}$ and the resulting algebraic resp. differential equation (put the order term equal to zero) is solved for $y$, leading to an approximation for $f$.

The role played in Number Theory can be viewed into by consulting papers by F. Beukers [15], D. V. Chudnovsky and G. V. Chudnovsky [54]-[56], [58], G. V. Chudnovsky [62], K. Mahler [144]-[146], V. N. Sorokin [184], [185] (don't forget the famous irrationality result on $\zeta(3)$ by Apéry) and some sidelines into the theory of differential equations by looking at D. V. Chudnovsky and G. V. Chudnovsky [53], [57].

Parallel to this development there have been several generalisations to the multivariate case cf. C. Brezinski [24], Cl. Chaffy [45], J. S. R. Chisholm [46], [47], J. S. R. Chisholm and P. R. Graves-Morris [48], J. S. R. Chisholm and R. Hugh Jones [49], J. S. R. Chisholm and J. McEwan [50], P. R. Graves-Morris [88], P. R. Graves-Morris, R. Hugh Jones and G. J. Makinson [91], R. Hugh Jones and G. J. Makinson [105] (and many other publications from the Canterbury group), A. M. Cuyt [68]-[73], A. M. Cuyt and B. M. Verdonk [74], A. M. Cuyt, H. Werner and L. Wuytack [75], G. John and C. H. Lutterodt [120], J. Karlsson and H. Wallin [126], D. Levin [130], C. H. Lutterodt [139, 140], P. Sablonniere [176], H. Werner [194], [195]. We will not look into this subject here.

Returning to the one variable case, we recollect that an important tool in the study of convergence is the study of (solutions of) recurrence relations: in the ordinary Padé table there is a fruitful connection between sequences of approximants and continued fractions! It already started with $G$. Frobenius [84] and there have been important results as early as for instance $R$. de 
Montessus de Ballore [149], R. Pringsheim [172], E. B. van Vleck [191]. There have appeared several books on continued fractions of. A. Ya. Khinchin [106] (of course also Hovanskii), W. B. Jones and W. J. Thron [121], O. Perron [167], H. S. Wall [193] (it is good to realize that usually the inverted Padé denominators - for a polynomial of degree $k$ look at $z^{k} P\left(z^{-1}\right)$ - are nothing else but polynomials orthogonal with respect to a (sometimes indefinite) innerproduct on the space of all polynomials).

Looking at simultaneous approximants, it is obvious to try to lind a generalisation of the continued fraction concept (already H. Padé [158] found all "regular algorithms" in a Padé table of type I for $n=2$; in [159] he gave several regular algorithms in the case of general $n$ ). Here we have to turn to C. G. J. Jacobi [117] (the length of the recurrence relation is increased by 1 compared to the ordinary continued fraction) and $O$. Perron [166] for the general case. We also have to mention P. Bachmann [10], Ch. Hermite [104], S. Pincherle [168].

After the introduction of what is nowadays called the Jacobi-Perron algorithm, the interest went into several directions.

One of the main areas of interest was in Number Theory (recovering linear or algebraic dependence, transcendency, calculation of units in number fields, calculation of best (simultaneous) rational approximants, etc.) cf. A. J. Brentjes[21], [22], V. Brun [42], [43], H. R. P. Ferguson and R. W. Forcade [83], R. Güting [96]-[98], W. Jurkat, W. Kratz and A. Peyerimhoff [123], N. Pipping [169], E. S. Selmer [179], G. Szekeres [190], G. F. Voronoi [192].

The Jacobi-Perron algorithm was studied (and extended) by L. Bernstein [14], M. G. de Bruin [26], [30]-[32], [34], M. G. de Bruin and L. Jacobsen [40], [41], P. van der Cruyssen [64]-[67], E. Dubois [81], L. Jacobsen [118], P. Levrie [131], H. Padé [157]-[159], R. Paysant Le Roux and E. Dubois [165], H. Rütishauser [175], F. Schweiger [178].

Other generalisations (vector- or matrix valued, more variable-case sometimes) were treated by M. Hallin [99]-[102], J. van Iseghem [109], [111], Alphonse Magnus [141]-[143], J. A. Murphy and M. R. O'Donohue [150], V. I. Parusnikov [160]-[164].

Finally, special attention must be paid to the concept of a branched continued fraction, almost automatically leading to multivariate approximation: D. I. Bodnar [16], P. I. Bodnarchuk [17], Kh. I. Kuchminskaya [127], [128], Kh. I. Kuchminskaya and W, Siemaszko [129], V. Ya. Skorobogatko [181] - a very valuable source and important entry point for the vast amount of publications on the subject, of which only very few have been translated up to now - [182].

As the reader can see, it is necessary to restrict ourselves something in the choice of material for the sequel (l'embarras du choix): from now on we will look into the type II polynomials for general $n$ (the Padé-n-table) and one of their "regular algorithms" (the $C$-n-fraction) only. For the proofs the reader is referred to the references (a.o. [26]-[41]). 


\section{The Padé-n-table}

Consider $n(n \geqslant 1)$ formal power series in $z$ with complex coefficients

$$
f_{j}(z)=\sum_{k=0}^{\infty} c_{k}^{(j)} z^{k}, \quad c_{0}^{(j)} \neq 0(1 \leqslant j \leqslant n)
$$

(the condition that the constant terms do not vanish has been added for sake of simplicity only, a simple change in the definitions in the sequel will make it possible to treat those cases where one (or more) functions vanish at the origin.)

Define for the non-negative numbers $\varrho_{0}, \varrho_{1}, \ldots, \varrho_{n}$, with $\sigma=\varrho_{0}+\varrho_{1}+\ldots$ $\ldots+\varrho_{n}$, for $j=1,2, \ldots, n$ the "building blocks" $D^{(j)}=D^{(j)}\left(\varrho_{0}, \varrho_{1}, \ldots, \varrho_{n}\right)$ by

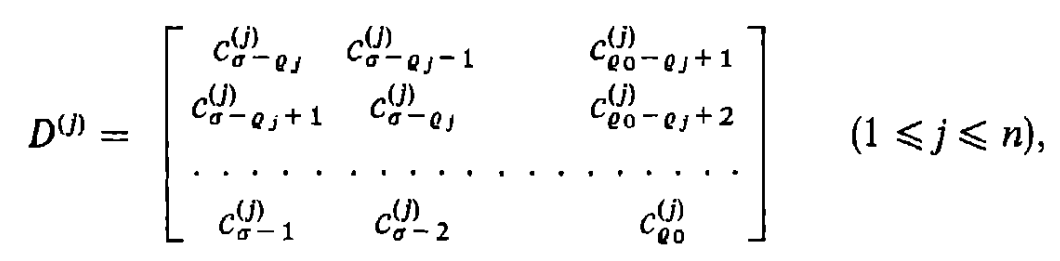

(for $\varrho_{j}=0$ the block is empty) and the "augmented" blocks $\tilde{D}^{(j)}$ $=\tilde{D}^{(\jmath)}\left(\varrho_{0}, \varrho_{1}, \ldots, \varrho_{n}\right)$ by

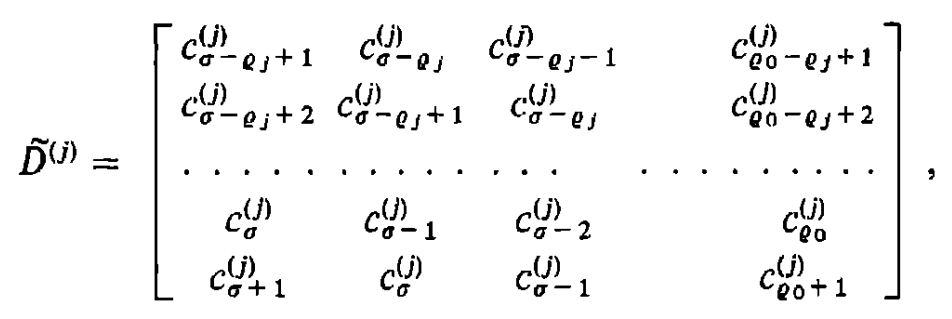

Furthermore we introduce the $\left(\sigma-\varrho_{0}\right) \times\left(\sigma-\varrho_{0}\right)$ determinant $D=D\left(\varrho_{0}, \varrho_{1}, \ldots\right.$ $\ldots, \varrho_{n}$ ) by

$$
D=\operatorname{det}\left[\begin{array}{c}
D^{(1)} \\
\vdots \\
D^{(n)}
\end{array}\right]
$$

and the $\left(\sigma-\varrho_{0}+n\right) \times\left(\sigma-\varrho_{0}+1\right)$ matrix $\tilde{D}$ by

$$
\tilde{D}=\left[\begin{array}{c}
\tilde{D}^{(1)} \\
\vdots \\
\tilde{D}^{(n)}
\end{array}\right]
$$

Throughout this paper it is tacitly assumed that $c_{k}^{(n)}=0$ for $k<0$ and that empty building blocks are omitted.

Consider now the type II problem of finding polynomials

$$
P_{j}(z)=P_{j}\left(\varrho_{0}, \varrho_{1}, \ldots, \varrho_{n} ; z\right) \quad(j=0,1, \ldots, n)
$$


satisfying

$$
\begin{aligned}
& \operatorname{deg} P_{J}(z) \leqslant \sigma-\varrho_{J} \quad(j=0,1, \ldots, n), \\
& P_{0}(z) f_{j}(z)-P_{j}(z)=O\left(z^{\sigma+1}\right) \quad(j=0,1, \ldots, n) .
\end{aligned}
$$

Then we have the following theorem:

THEOREM 1. If $D\left(\varrho_{0}, \varrho_{1}, \ldots, \varrho_{n}\right) \neq 0$, then the solution of $(4 a, b)$, which is unique after the normalization $P_{0}\left(\varrho_{0}, \varrho_{1}, \ldots, \varrho_{n} ; 0\right)=1$, is given by

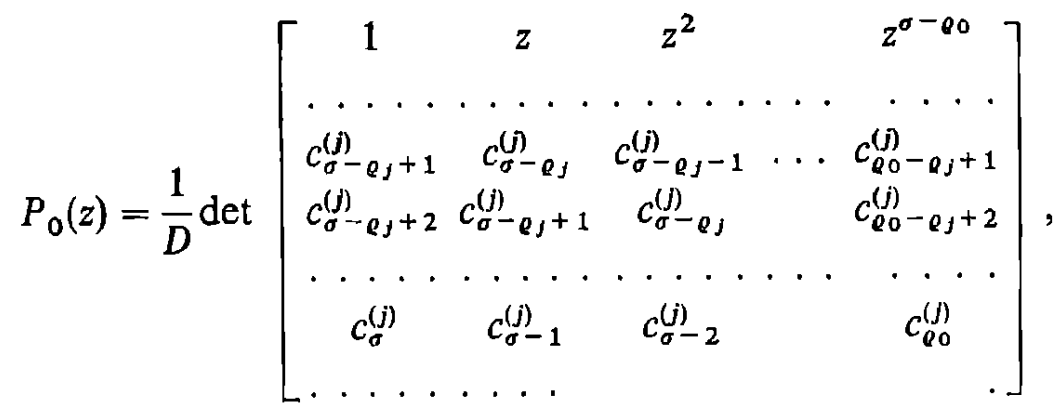

(6) $\quad P_{i}(z)$

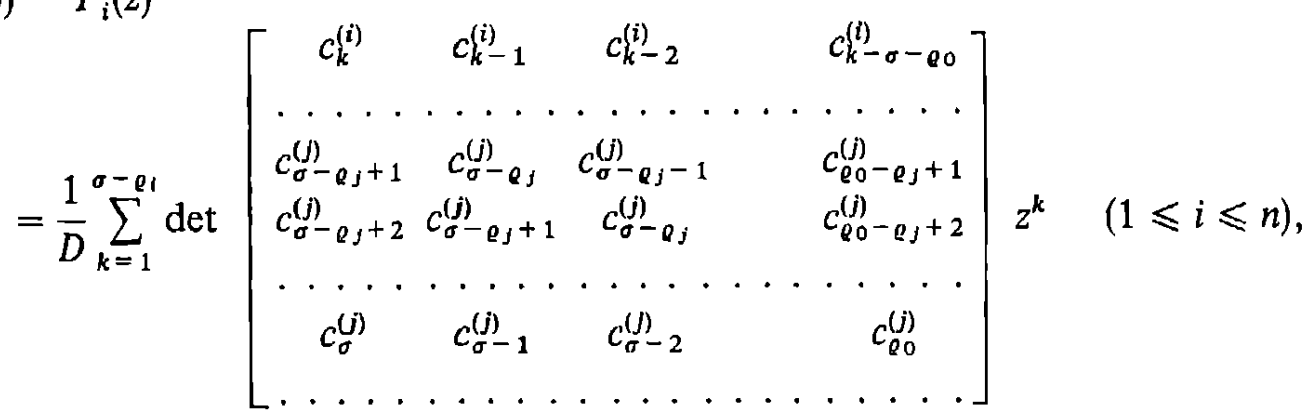

(7) $\quad P_{0}(z) f_{i}(z)-P_{i}(z)$

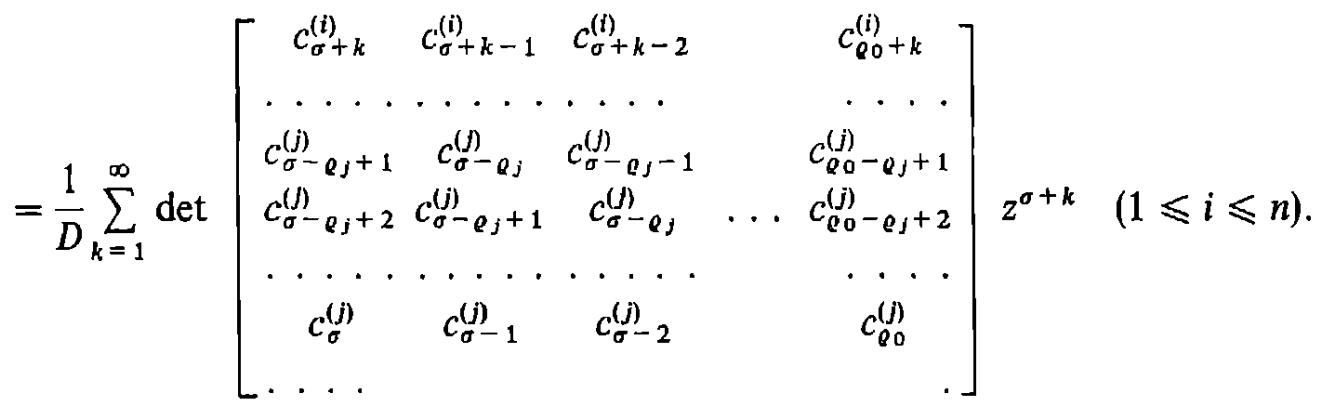

From now on we will assume that we are always in the situation of having a unique solution after the normalisation used before.

Definition 1. The $n$-tuple $\left(f_{1}, f_{2}, \ldots, f_{n}\right)$ will be called regular if

$$
D\left(\varrho_{0}, \varrho_{1}, \ldots, \varrho_{n}\right) \neq \dot{0} \quad \text { for all }\left(\varrho_{0}, \varrho_{1}, \ldots, \varrho_{n}\right) \text {, }
$$


and semi-regular if

(8b) $D\left(\varrho_{0}, \varrho_{1}, \ldots, \varrho_{n}\right) \neq 0$ for all $\left(\varrho_{0}, \varrho_{1}, \ldots, \varrho_{n}\right)$ with $\varrho_{0} \geqslant \varrho_{J}-1(1 \leqslant j \leqslant n)$.

Placing at each point with non-negative integer coordinates in $(n+1)$-space the unique solution $(5,6)$ of problem $(4 a, b)$, we arrive at the configuration that will be referred to as the Padé-n-table; for a semi-regular $n$-tuple of functions only the "upper half" of the table is defined. Introduce the concept of normality in the same way as was done for the ordinary Padé table (this is actually the case $n=1$ in the preceding formulae!) by

Definition 2. The point $\left(\varrho_{0}, \varrho_{1}, \ldots, \varrho_{n}\right)$ in the Padé- $n$-table for the $n$-tuple $\left(f_{1}, f_{2}, \ldots, f_{n}\right)$ is called normal if the solution $(5,6)$ belonging to the point, does not appear at any other point in the Padé- $n$-table.

An important result is now the following:

THEOREM 2. For a point $\left(\varrho_{0}, \varrho_{1}, \ldots, \varrho_{n}\right)$ in the Padé-n-table for a (semi-) regular n-tuple of formal power series the following properties are equivalent:

(a) $\left(\varrho_{0}, \varrho_{1}, \ldots, \varrho_{n}\right)$ is normal.

(b) $\operatorname{deg} P_{j}(z)=\sigma-\varrho_{j}(0 \leqslant j \leqslant n), P_{0}(z) f_{j}(z)-P_{j}(z) \neq O\left(z^{\sigma+2}\right)$ for at least one $j \in\{1,2, \ldots, n\}$.

(c) The determinants $D\left(\varrho_{0}, \varrho_{1}, \ldots, \varrho_{n}\right), D\left(\varrho_{0}+1, \varrho_{1}, \ldots, \varrho_{n}\right), D\left(\varrho_{0}, \varrho_{1}, \ldots\right.$ $\left.\ldots, \varrho_{j-1}, \varrho_{j}+1, \varrho_{j+1}, \ldots, \varrho_{n}\right)(1 \leqslant j \leqslant n)$ are different from zero and rank $D=\sigma-\varrho_{0}+1$.

Very few situations of completely regular or normal Padé-n-tables are known, most of them appear in the following list:

(a) the exponential function system $\left(e^{\lambda_{j} z}, 1 \leqslant j \leqslant n\right)$ with $\lambda_{j} \neq 0, \lambda_{j} \neq \lambda_{i}$; normal, explicit formulae known (Ch. Hermite, $H$. Jager).

(b) the binomial function system $\left((1-z)^{\lambda_{j}}, 1 \leqslant j \leqslant n\right)$ with $\lambda_{j} \notin \mathscr{Z}$, $\lambda_{j}-\lambda_{i} \notin \mathscr{Z}$; normal, explicit formulae known (H. Jager).

(c) the logarithmic function system $\left(\log ^{j}(1-z), 1 \leqslant j \leqslant n\right)$ with $\varrho_{0} \leqslant \varrho_{1}$ $\leqslant \ldots \leqslant \varrho_{n}$; normal (H. Jager; (b) and (c) together in one normality theorem by A. Baker).

(d) Angelesco-systems; explicit formulae (A. Angelesco, E. M. Nikishin, V. N. Sorokin).

(e) the hypergeometric function systems $\left({ }_{2} F_{1}\left(a_{j}, 1 ; a_{j}+b ; z\right), 1 \leqslant j \leqslant n\right)$ with $a_{j}, a_{j}+b \notin \mathscr{Z} \backslash \mathcal{N}, a_{i}-a_{j} \notin \mathscr{Z},\left({ }_{1} F_{1}\left(1 ; c_{j} ; z\right), 1 \leqslant j \leqslant n\right)$ with $c_{j} \notin \mathscr{X} \backslash \mathscr{N}$, $c_{i}-c_{j} \notin \mathscr{Z},\left({ }_{2} F_{0}\left(a_{j}, 1 ; z\right), 1 \leqslant j \leqslant n\right)$ with $a_{j} \notin \mathscr{Z} \backslash \mathscr{N}, a_{i}-a_{j} \notin \mathscr{Z}$; semi-regular, normal for $\varrho_{0} \geqslant \varrho_{j}$, for the second and third system explicit formulae (M. G. de Bruin).

(f) the hypergeometric function system $\left({ }_{1} F_{1}\left(1 ; c ; \lambda_{j} z\right), 1 \leqslant j \leqslant n\right)$ with $\lambda_{j} \neq 0, \lambda_{j} \neq \lambda_{i}$; semi-regular, explicit formulae known (A. I. Aptekarev).

(g) the $q$-hypergeometric function systems $\left({ }_{2} \Phi_{1}\left(\left(A, \gamma_{j}+\beta\right),(1,1) ;\left(C, \gamma_{j}\right) ; z\right)\right.$, $1 \leqslant j \leqslant n)$ with $A \neq q^{\gamma_{j}+\beta+k}, C \neq q^{\gamma_{j}+k}, C q^{\beta} \neq A q^{k}$ for $k \geqslant 0, q^{\gamma_{j}-\gamma_{j}+k}$ $\neq 1(i \neq j)$ for $k \in \mathscr{Z},\left({ }_{1} \Phi_{1}\left((1,1) ;\left(C, \gamma_{j}\right) ; z\right), 1 \leqslant j \leqslant n\right)$ with $C \neq q^{\gamma_{j}+k}$ for $k \geqslant 0$, 
$q^{\gamma_{i}-\gamma_{j}+k} \neq 1(i \neq j)$ for $k \in \mathscr{Z},\left({ }_{2} \Phi_{0}\left(\left(A, \alpha_{j}\right),(1,1) ; z\right), 1 \leqslant j \leqslant n\right)$, with $A \neq q^{\alpha_{j}+k}$ for $k \geqslant 0, q^{\alpha_{i}-\alpha_{j}+k} \neq 1(i \neq j)$ for $k \in \mathscr{Z}$; in all three cases also $q \in \mathscr{C} \backslash\{0,1\}$, $q^{k} \neq 1(k \geqslant 1)$, semi-regular, normal for $\varrho_{0} \geqslant \varrho_{j}$, for the second and third system explicit formulae (M. G. de Bruin).

In the last example the $q$-hypergeometric functions are introduced according to the following notation:

$$
, \Phi_{s}\left(\left(A_{1}, \alpha_{1}\right), \ldots,\left(A_{r}, \alpha_{r}\right) ;\left(C_{1}, \gamma_{1}\right), \ldots,\left(C_{s}, \gamma_{s}\right) ; z\right)=\sum_{k=0}^{\infty} \frac{\prod_{i=1}^{r}\left(A_{i}, \alpha_{i} ; q\right)_{k}}{\prod_{j=1}^{s}\left(C_{j}, \gamma_{j} ; q\right)_{k}} \frac{z^{k}}{(1,1 ; q)_{k}},
$$

with the generalization of the ascending factorial (Pochhammer's symbol) given by

$$
(A, \alpha ; q)_{0}=1, \quad(A, \alpha ; q)_{n}=\left(A-q^{\alpha}\right)\left(A-q^{\alpha+1}\right) \ldots\left(A-q^{\alpha+n-1}\right) \quad(n \geqslant 1) .
$$

One might wonder how the block structure of the ordinary Padé table is translated for the type of multidimensional table that has just been defined. A simple example shows the problem we have to face.

Suppose that the point $\left(\varrho_{0}, \varrho_{1}, \ldots, \varrho_{n}\right)$ is normal and has as solution to problem $(4 \mathrm{a}, \mathrm{b})$ a set of polynomials with actual degrees $\left(p_{0}, p_{1}, \ldots, p_{n}\right)$, then automatically $\sigma-\varrho_{j}=p_{j}$ for $1 \leqslant j \leqslant n$. Adding all the equations and inserting the definition of $\sigma$, we find the condition

$$
p_{0}+p_{1}+\ldots+p_{n} \equiv 0(\bmod n) \text {. }
$$

The difference between the case $n=1$ and $n \geqslant 2$ is obvious: for the ordinary Padé table this is no restriction at all! When $n \geqslant 2$, however, we have to put $p_{0}+p_{1}+\ldots+p_{n}=k n$, to satisfy the condition and we find $\varrho_{j}=k-p_{j}$, $1 \leqslant j \leqslant n$. Here we see another condition on the $p$ 's:

$$
n \max _{0 \leqslant j \leqslant n} p_{j} \leqslant p_{0}+p_{1}+\ldots+p_{n}
$$

(note that this problem of having conditions on the p's does also not arise in the case of the type I polynomials.)

Looking better into the subject, it is a matter of simple inequalities to prove the following theorem

Theorem 3. Let $\left\{P_{j}(z) / P_{0}(z), 1 \leqslant j \leqslant n\right\}$ appear at $\left(\varrho_{0}, \varrho_{1}, \ldots, \varrho_{n}\right)$ in the Padé-n-table for an n-tuple of formal power series such that $(4 \mathrm{a}, \mathrm{b})$ has a unique solution up to a multiplicative constant. Write this solution in its simplest terms and define

$$
\begin{gathered}
G C D\left(P_{0}, P_{1}, \ldots, P_{n}\right)=1 ; \quad P_{0}(0)=1, \quad P_{j}(0)=c_{0}^{(j)} \quad(1 \leqslant j \leqslant n), \\
\operatorname{deg} P_{j}=p_{j}(0 \leqslant j \leqslant n), \quad P_{0} f_{j}-P_{j}=d_{j} z^{k_{j}}+\ldots, \quad d_{j} \neq 0, k_{j}<\infty(1 \leqslant j \leqslant n), \\
r_{j} \text { follows from } n k_{j}=p_{0}+p_{1}+\ldots+p_{n}+r_{j}, \quad r_{j} \geqslant 0(1 \leqslant j \leqslant n) .
\end{gathered}
$$


Finally define

Then we have

$$
r=\min _{1 \leqslant j \leqslant n} r_{j}
$$

(a) If $p_{0}+p_{1}+\ldots+p_{n} \equiv 0(\bmod n)$ and $\varrho_{j}=\left(p_{0}+p_{1}+\ldots+p_{n}\right) / n-p_{j}$, $1 \leqslant j \leqslant n$, then

$$
\left(\varrho_{0}, \varrho_{1}, \ldots, \varrho_{n}\right) \text { is normal } \Leftrightarrow r=0 .
$$

(b) If $r \geqslant 1$, the set to which the n-tuple belongs, consists of at least two points. They are just the points having all coordinates non-negative, taken from the following sets.

A. For $p_{0}+p_{1}+\ldots+p_{n}=m n$ with $m \geqslant 0$ fixed:

$$
\left(\tilde{\varrho}_{0}+v_{0}, \tilde{\varrho}_{1}+v_{1}, \ldots, \tilde{\varrho}_{n}+v_{n}\right) \text { with } \tilde{\varrho}_{j}=m-p_{j} \quad(0 \leqslant j \leqslant n), r=n v(v \geqslant 1)
$$

and (1) $v_{0}+v_{1}+\ldots+v_{n}=w,(2) \max v_{j} \leqslant \min (w, v)$, (3) $\min v_{j} \geqslant w-n v$ where $0 \leqslant w \leqslant(n+1) v$.

B. For $p_{0}+p_{1}+\ldots+p_{n}=m n+n-k$ with $1 \leqslant k \leqslant n-1, m \geqslant 0$ both fixed:

$$
\left(\tilde{\varrho}_{0}+v_{0}, \tilde{\varrho}_{1}+v_{1}, \ldots, \tilde{\varrho}_{n}+v_{n}\right) \text { with } \tilde{\varrho}_{j}=m-p_{j}(0 \leqslant j \leqslant n), r=n v+k(v \geqslant 0)
$$

and (1) $v_{0}+v_{1}+\ldots+v_{n}=w+n-k+1$, (2) $\max v_{j} \leqslant \min (w, v)+1$, (3) $\min v_{j} \geqslant w-n v-k+1$ where $0 \leqslant w \leqslant(n+1) v+k$.

Remark. The conditions follow from the fact that there should exist a non-negative integer $x$, such that $x+p_{j} \leqslant \sigma-\varrho_{j}(0 \leqslant j \leqslant n), x+k_{j} \geqslant \sigma+1$ $(1 \leqslant j \leqslant n)$.

Adding the last set of inequalities, inserting $n \sigma=\left(\sigma-\varrho_{0}\right)+\left(\sigma-\varrho_{1}\right)+\ldots$ $\ldots+\left(\sigma-\varrho_{n}\right)$, and inserting the first set of inequalities, we find $r_{j} \geqslant 0$ and with $r=\min r_{j}$ it turns out that the cóordinates of the points where the rational functions appear should satisfy $p_{j}+x \leqslant \sigma-\varrho_{j} \leqslant p_{j}+r(0 \leqslant j \leqslant n)$.

For $n=2$ (a three dimensional table) we easily deduce the following pictures:

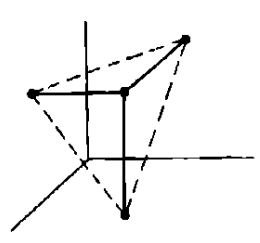

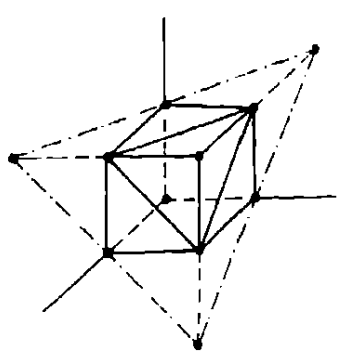

$v=1, k=0$

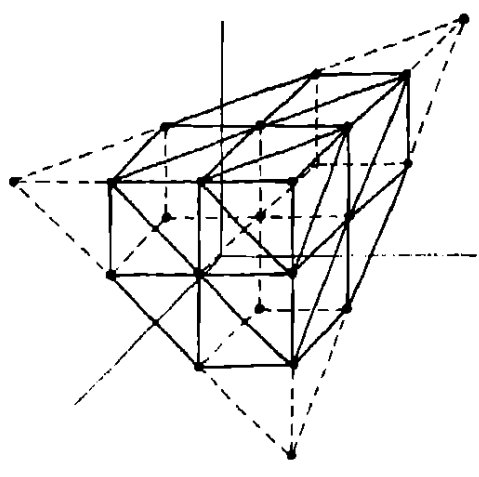

$v=1 \quad k=1$ 
Now we turn our attention towards walks in the table. Restricting ourselves to the case $n=2$ for sake of simplicity, an algorithm connected with the path $\left(\varrho_{0}(k), \varrho_{1}(k), \varrho_{2}(k)\right)$ will be called regular (cf. [158]) if we have the following situation

(a) the points $\left(\varrho_{0}(k), \varrho_{1}(k), \varrho_{2}(k)\right)$ admit a unique solution to problem $(4 a, b)$

(b) $\sigma(k)=\varrho_{0}(k)+\varrho_{1}(k)+\varrho_{2}(k)$ is strictly increasing in $k$,

(c) the determinants

$$
\operatorname{det}\left[\begin{array}{lll}
P_{0}(k ; z) & P_{0}(k+1 ; z) & P_{0}(k+2 ; z) \\
P_{1}(k ; z) & P_{1}(k+1 ; z) & P_{1}(k+2 ; z) \\
P_{2}(k ; z) & P_{2}(k+1 ; z) & P_{2}(k+2 ; z)
\end{array}\right]
$$

all are monomials in $z$,

(d) the three sequences of polynomials satisfy the same recurrence relation

$$
\begin{array}{r}
P_{j}(k+3 ; z)=a_{k}(z) P_{j}(k+2 ; z)+b_{k}(z) P_{j}(k+1 ; z)+c_{k}(z) P_{j}(k ; z) \\
(j=0,1,2 ; k \geqslant 1),
\end{array}
$$

where the coefficients are polynomials in $z$ of fixed degrees and orders.

Using the same method as $\mathrm{H}$. Padé did, it is possible to find all regular algorithms in the Padé-2-table. It turns out that there are basically only three regular algorithms in the table (although of course relaxation of the conditions leads to other, quite interesting algorithms: for instance when walking along a path of constant $\sigma$, i.e. an anti-diagonal, cf. [95]) which are given below

A. coefficients $1, \beta_{k} z, \gamma_{k} z^{2}$ with $\gamma_{k} \neq 0$; a generalised stepline, the coordinates of the points show a relative increase of $(1,0,0),(0,1,0),(0,0,1)$ ad inf. (a $C$-2-fraction).

B. coefficients $1+\alpha_{k} z, \beta_{k} z, \gamma_{k} z^{2}$ with $\gamma_{k} \neq 0$; an ordinary stepline in a plane perpendicular to one of the axes, the coordinates of the points show a relative increase of $(1,0,0),(0,1,0)$ or $(1,0,0),(0,0,1)$ or $(0,1,0),(0,0,1)$ ad inf.

C. coefficients $1+\alpha_{k} z, \beta_{k} z+\gamma_{k} z^{2}, \delta_{k} z^{2}$ with $\delta_{k} \neq 0$; a walk parallel to one of the axes, the coordinates of the points show a relative increase of $(1,0,0)$ or $(0,1,0)$ or $(0,0,1)$ ad inf.

The method of deriving the result quoted above, shows that there is no hope to achieve anything when solving the problem for general $n$ in that way (the first step is to find all admissable triplets of points (a) that satisfy (b, c), combine these amongst themselves to find all quadruplets of points such that the first three and the last three points both satisfy $(b, c)$ - this already leads to 261 quadruplets, giving 87 basic situations if we allow for cyclic permutations of the coordinates - and finally the pattern for the coefficients of the recurrence relation has to be calculated; this gives 6 different patterns, of which only 3 satisfy the requirements for regularity given above). 
In the Padé-n-table there exist of course variants on the algorithms $\mathrm{B}$ and $\mathrm{C}$ (this time there are more choices, but the reader has to bear in mind, that keeping one or more of the coordinates fixed - barring the first coordinate $\varrho_{0}-$ means nothing else than not using the function(s) having the same index as the coordinate(s): we are in the situation of a table for $m<n$ functions!)

Now the restriction will be made to one special type of algorithm: the generalisation of the ordinary stepline (type A given before). It is possible to prove the following theorem.

THEOREM 4. Let $k$ be a non-negative integer and let the stepline

$$
\begin{aligned}
(k, 0, \ldots, 0),(k+1,0, \ldots, 0),(k+1,1,0, \ldots, 0), \\
\ldots,(k+1,1, \ldots, 1),(k+2,1, \ldots, 1),(k+2,2,1, \ldots, 1), \ldots
\end{aligned}
$$

in the Padé-n-table for the functions

$$
f_{j}(z)=\sum_{k=0}^{\infty} c_{k}^{(j)} z^{k} \quad(1 \leqslant j \leqslant n)
$$

be normal. Then the polynomials $P_{0}(m ; z), P_{1}(m ; z), \ldots, P_{n}(m ; z)$ (the points are numbered consecutively $0,1,2, \ldots, n, n+1, n+2, \ldots)$ all satisfy the same recurrence relation

(9a) $X_{m}=X_{m-1}+a_{m}^{(n)} X_{m-2}+a_{m}^{(n-1)} X_{m-3}+\ldots+a_{m}^{(1)} X_{m-n-1} \quad(m \geqslant 1)$,

with for each sequence a different set of initial values

$$
\begin{aligned}
& P_{j}(-m ; z)=\delta_{m+j, n+1} \quad(0 \leqslant j \leqslant n ; 1 \leqslant m \leqslant n), \\
& P_{0}(0 ; z)=1, \quad P_{j}(0 ; z)=\sum_{i=0}^{k} c_{i}^{(j)} z^{i} \quad(1 \leqslant j \leqslant n) .
\end{aligned}
$$

The coefficients in the recurrence relation have the form

$$
a_{m}^{(j)}= \begin{cases}a_{m, j} z^{k+m} & (1 \leqslant m \leqslant j \leqslant n), \\ a_{m, j} z^{\min (n+1-j, m)} & (1 \leqslant j \leqslant m \leqslant n), \\ a_{m, j} z^{n+1-j} & (j \geqslant n+1),\end{cases}
$$

where the constants in the monomials satisfy $a_{j, m} \in \mathscr{C}$ and $a_{1, m} \neq 0(m \geqslant 1)$.

Here we see clearly the connection with recurrence relations of length greater than or equal to three; this subject will be treated in the next section. As a final remark - a matter which will not be elaborated upon - it must be mentioned that the concept of Padé approximation can be introduced through so-called Padé-type-approximants, using a straightforward generalisation of the theory of C. Brezinski [23] (cf. [37]). 


\section{Generalised Continued Fractions}

The type of generalisation to be considered here is inspired by the Jacobi -Perron algorithm, which actually stems from a Euclidean algorithm for the simultaneous approximation of $n$ real numbers by $n$ rational numbers with a common denominator.

There are many ways to introduce the concept that plays the main role in this section, due to space limitations only one method will be given; for other methods (consecutive linear fractional transformations in $n$ variables etc.) the reader can consult for instance [26], [30].

Let $n+1$ sequences of complex numbers be given

$$
b_{m}, a_{m}^{(n)}, a_{m}^{(n-1)}, \ldots, a_{m}^{(1)}(m \geqslant 1), \quad b_{m} \neq 0 \quad(m \geqslant 1),
$$

along with $n$ starting values

$$
b_{0}^{(n)}, b_{0}^{(n-1)}, \ldots, b_{0}^{(1)} .
$$

The set of data will usually be given by the notation

$$
\left[\begin{array}{cccccc} 
& a_{1}^{(1)} & a_{2}^{(1)} & & a_{m}^{(1)} & \ldots \\
b_{0}^{(1)} & a_{1}^{(2)} & a_{2}^{(2)} & & a_{m}^{(2)} & \ldots \\
b_{0}^{(2)} & a_{1}^{(3)} & a_{2}^{(3)} & & a_{m}^{(3)} & \ldots \\
\ldots \ldots & \ldots & \ldots & \ldots & \ldots & \ldots \\
b_{0}^{(n-1)} & a_{1}^{(n)} & a_{2}^{(n)} & & a_{m}^{(n)} & \ldots \\
b_{0}^{(n)} & b_{1} & b_{2} & & b_{m} & \ldots
\end{array}\right] .
$$

Definition 3. Given a set of data (10), an $n$-fraction is defined by its sequence of $n$-tuples of approximants $\left(A_{m}^{(j)} / A_{m}^{(0)}, 1 \leqslant j \leqslant n\right), m \geqslant 0$. All sequences $\left(A_{m}^{(j)}, m \geqslant 0\right), 0 \leqslant j \leqslant n$, satisfy the same recurrence relation

$$
X_{m}=b_{m} X_{m-1}+a_{m}^{(n)} X_{m-2}+a_{m}^{(n-1)} X_{m-3}+\ldots+a_{m}^{(1)} X_{m-n-1} \quad(m \geqslant 1),
$$

with for each sequence a different set of initial values

$$
\begin{gathered}
A_{-m}^{(j)}=\delta_{m+j, n+1} \quad(0 \leqslant j \leqslant n ; 1 \leqslant m \leqslant n), \\
A_{\delta}^{(n)}=1, \quad A_{\delta}^{(j)}=b_{0}^{(j)} \quad(1 \leqslant j \leqslant n) .
\end{gathered}
$$

We then have the formalism to calculate the numerators and denominators (for the moment only formally, existence and convergence will be treated lateron) using matrix-multiplication. Introducing the following matrices

$$
\mathscr{A}_{0}=\left[\begin{array}{ccccc}
1 & 0 & 0 & & 0 \\
b_{0}^{(1)} & 1 & 0 & & 0 \\
b_{0}^{(2)} & 0 & 1 & & 0 \\
\ldots & & & \ldots & . \\
b_{0}^{(n)} & 0 & & 0 & 1
\end{array}\right] ;
$$




$$
\mathscr{B}_{m}=\left[\begin{array}{ccccc}
b_{m} & 1 & 0 & & 0 \\
a_{m}^{(n)} & 0 & 1 & & 0 \\
\cdots & \ldots & \ldots & \ldots & \ldots \\
a_{m}^{(2)} & 0 & & 0 & 1 \\
a_{m}^{(1)} & 0 & & 0 & 0
\end{array}\right], \quad \mathscr{A}_{m}=\mathscr{A}_{m-1} \mathscr{B}_{m} \quad(m \geqslant 1)
$$

it is a simple matter of mathematical induction to prove

$$
\mathscr{A}_{m}=\left[\begin{array}{lll}
A_{m}^{(0)} & & A_{m-n}^{(0)} \\
\cdots & \cdots & \cdots \\
A_{m}^{(n)} & & A_{m-n}^{(n)}
\end{array}\right]
$$

The concept of a terminating $n$-fraction is now defined easily: there is just a finite set of data, terminating with a certain index, say $k$. The sequences of denominators and numerators - defining the approximants - then are also terminated after index $k$; the value of a (non) terminating $n$-fraction is then nothing else but the $n$-tuple of values $A_{k}^{(j)} / A_{k}^{(0)}, 1 \leqslant j \leqslant n$ (or - in the non-terminating case - the limit for $k \rightarrow \infty$ of these expressions). Fundamental for existence/convergence is the following theorem

THEOREM 5. Consider a non-terminating n-fraction (10) with finite limits. If $a_{1}^{(1)}, a_{2}^{(1)}, \ldots, a_{k}^{(1)} \neq 0$, then any two of the following formulae imply the third:

$$
\left[\begin{array}{c}
\xi_{0}^{(1)} \\
\vdots \\
\xi_{0}^{(n)}
\end{array}\right]=\left[\begin{array}{lllll} 
& a_{1}^{(1)} & a_{k-1}^{(1)} & a_{k}^{(1)} \\
b_{0}^{(1)} & a_{1}^{(2)} & a_{k-1}^{(2)} & \xi_{k}^{(1)} \\
\ldots \ldots & \ldots & \ldots & \ldots & \ldots \\
b_{0}^{(1)-1)} & a_{1}^{(n)} & & a_{k-1}^{(n)} & \xi_{k}^{(1)-1)} \\
b_{0}^{(n)} & b_{1} & & b_{k-1} & \xi_{k}^{(n)}
\end{array}\right]
$$

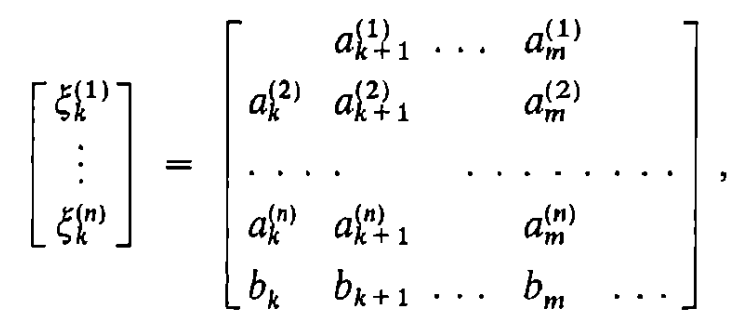$$
\left[\begin{array}{c}
\xi_{0}^{(1)} \\
\vdots \\
\xi_{0}^{(n)}
\end{array}\right]=\left[\begin{array}{ccccc} 
& a_{1}^{(1)} & a_{2}^{(1)} & a_{m}^{(1)} & \ldots \\
b_{0}^{(1)} & a_{1}^{(2)} & a_{2}^{(2)} & & a_{m}^{(2)} \\
\ldots \ldots & \ldots & \ldots & \\
\ldots & \ldots & \ldots \\
b_{0}^{(n-1)} & a_{1}^{(n)} & a_{2}^{(n)} & a_{m}^{(n)} & \ldots \\
b_{0}^{(n)} & b_{1} & b_{2} & b_{m} & \ldots
\end{array}\right]
$$ 
There is an important connection between convergence of these $n$-fractions and the behaviour of the solution space of the linear recurrence relation that plays the key-role in the definition of the approximant $n$-tuples. We have the following theorem due to $P$. van der Cruyssen [64].

THEOREM 6. Consider the recurrence relation

$$
\begin{aligned}
X_{k}=b_{k} X_{k-1}+a_{k}^{(n)} X_{k-2}+a_{k}^{(n-1)} X_{k-3}+\ldots+a_{k}^{(1)} X_{k-n-1}, \\
\text { with } a_{k}^{(1)} \neq 0 \quad(k \geqslant 1) .
\end{aligned}
$$

The solution space is an $(n+1)$-dimensional linear space over the complex numbers and $a$ basis can be given by those solutions that for instance satisfy $A_{-k}^{(j)}=\delta_{k+j, n+1} \quad(0 \leqslant k \leqslant n, 1 \leqslant j \leqslant n+1)$. Then the fractions $\left(A_{k}^{(j)} / A_{k}^{(n+1)}\right.$, $1 \leqslant j \leqslant n, k \geqslant 0$ ), we use suffix $n+1$ here instead of 0 , are the approximant $n$-tuples of the $n$-fraction

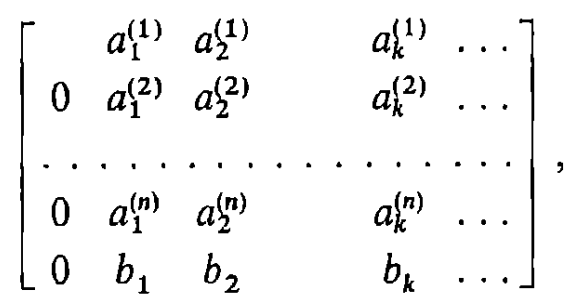

and the following statements are equivalent:

(a) There exists a dominant solution of (12) (i.e. $X_{k} / D_{k} \rightarrow 0$ for $k \rightarrow \infty$ for all sequences $\left(X_{k}\right)$ in an $n$-dimensional subspace of the solution space), for which the dominated subspace has a basis $\left(X_{k}^{(1)}\right),\left(X_{k}^{(2)}\right), \ldots,\left(X_{k}^{(n)}\right)$, satisfying

$$
\left|\begin{array}{lll}
X_{-n}^{(1)} & \ldots & X_{1}^{(1)} \\
\ldots & \ldots & \ldots \\
X_{-n}^{(n)} & \ldots & X_{1}^{(n)}
\end{array}\right| \neq 0
$$

(b) The n-fraction (13) converges to finite limits

$$
\lim _{k \rightarrow \infty} \frac{A_{k}^{(j)}}{A_{k}^{(n+1)}}=\xi^{(j)} \in \mathscr{C} \quad(1 \leqslant j \leqslant n)
$$

Here we see a method to derive convergence results for an $n$-fraction (13) from the knowledge about the solution space of a linear recurrence relation (12) and vice versa.

The reader might wonder why the type of continued fraction given before is of interest for simultaneous approximation in the Pade sense. The answer to this has already been given in Theorem 4: approximants along a generalised stepline in a normal Padé- $n$-table give rise to an $n$-fraction! Therefore it is now about time to introduce the analytic aspects of generalised continued fractions and this will be done together with the algorithmic aspects of the correspon- 
dence between $n$-tuples of formal power series and a generalisation of the $C$-fraction algorithm (cf. [106], [121], [167], [193] for the ordinary $C$-fraction).

Consider an $n$-tuple of formal power series $f_{k}^{(1)}, f_{k}^{(2)}, \ldots, f_{k}^{(n)}$ with complex coefficients (here the notation has been changed slightly from what happened up to now: the suffix is used to number the functions in an $n$-tuple and the index is used to number the steps in the algorithm).

Step 0 . We start with $k=0$.

(a) Take the first and second non-zero terms in $f_{0}^{(1)}-$ in case this power series is a monomial or identically zero, we turn to "interruption handling" denote these terms by $b_{1,0} z^{r(1,0)}$ resp. $a_{1,1} z^{r(1,1)}$. Use these to define $f_{1}^{(n)}$ by inverting the tail of the function

$$
f_{0}^{(1)}(z)=b_{1,0} z^{r(1,0)}+\frac{a_{1,1} z^{r(1,1)}}{f_{1}^{(n)}(z)}, \quad 0 \leqslant r(1,0)<r(1,1), f_{1}^{(n)}(z)=1+O(z)
$$

(b) Take the first non-zero term of $f_{0}^{(j)}$ and force the tail to have the same denominator as in (a), thereby defining $f_{1}^{(j-1)}, 2 \leqslant j \leqslant n$,

$$
\begin{aligned}
f_{0}^{(j)}(z)=b_{j, 0} z^{r(J, 0)}+\frac{f_{1}^{(j-1)}(z)}{f_{1}^{(n)}(z)} & \\
& 0 \leqslant r(j, 0), f_{1}^{(j-1)}(z)=O\left(z^{p}\right) \text { with } p>r(j-1,0) .
\end{aligned}
$$

We now have an $n$-tuple of functions with index 1 and $f_{1}^{(n)}(z)=1+O(z)$.

Step $k$. We start from an $n$-tuple $f_{k}^{(1)}, f_{k}^{(2)}, \ldots, f_{k}^{(n)}$.

A. $f_{k}^{(1)}(z)$ is not a monomial nor identically zero.

(a) As in step 0 , we use the function with suffix 1 , index $k$, to define the the function with suffix $n$, index $k+1$

$$
\begin{aligned}
& f_{k}^{(1)}(z)=a_{2, k} z^{r(2, k)}+\frac{a_{1, k+1} z^{r(1, k+1)}}{f_{k+1}^{(n)}(z)} \\
& 1 \leqslant r(2, k)<r(1, k+1), f_{k+1}^{(n)}(z)=1+O(z) .
\end{aligned}
$$

(b) As in step 0 , the functions with suffix $j$, index $k$, are used to define the functions with suffix $j-1$, index $k+1$.

$$
\begin{gathered}
f_{k}^{(j)}(z)=a(j+1, k) z^{r(j+1, k)}+\frac{f_{k+1}^{(j-1)}(z)}{f_{k+1}^{(n)}(z)}, \\
f_{k+1}^{(j-1)}(z)=O\left(z^{p}\right) \text { with } p>r(j+1, k)(2 \leqslant j \leqslant n-1), \\
f_{k}^{(n)}(z)=1+\frac{f_{k+1}^{(n-1)}(z)}{f_{k+1}^{(n+1}(z)}, \quad f_{k+1}^{(n-1)}(z)=O\left(z^{p}\right) \text { with } p>r(n, k) .
\end{gathered}
$$

B. $f_{k}^{(1)}(z)$ is a monomial or identically zero.

The first function cannot be used to define the denominator as in the previous cases. We assume that $f_{k}^{(1)}, f_{k}^{(2)}, \ldots, f_{k}^{(s)}$ all are monomials or 
identically zero. But $f_{k}^{(s+1)}$ is the first power series having at least two terms. This is called an interruption of order $s$ at index $k$. There are now two possibilities.

B1. It happens that $s=n$ : all power series have at most one non-zero term. Put $a_{j+1, k} z^{r(j+1, k)} \equiv f_{k}^{(j)}(z)(1 \leqslant j \leqslant n-1), b_{k}=1$ - the term $a_{1, k} z^{r(1, k)}$ has already been found in the previous step - and the algorithm terminates. Calculating backwards, we find that the original series must be the Taylor series of an $n$-tuple of rational functions for which $z=0$ is a regular point in the complex plane.

B2. Now $1 \leqslant s \leqslant n-1$. Put $a_{j+1, k} z^{r(j+1, k)} \equiv f_{k}^{(j)}(z) \quad(1 \leqslant j \leqslant s)$, $a_{j, m} z^{r(j, m)} \equiv 0(1 \leqslant j \leqslant s ; m \geqslant k+1)$, and define $f_{k+1}^{(n)}$ using two non-zero terms from $f_{k}^{(s+1) \text { ! }}$

Now repeat case A for the functions that are left over, i.e. for $f_{k}^{(s+1)}$, $f_{k}^{(s+2)}, \ldots, f_{k}^{(n)}$.

The algorithm now goes on until another interruption occurs; either it terminates or it does not, the result is called a $C$ - $n$-fraction. A compact notation for the result of the algorithm is given below:

$$
\left[\begin{array}{c}
f_{0}^{(1)}(z) \\
\vdots \\
f_{0}^{(n)}(z)
\end{array}\right]=\left[\begin{array}{cccc} 
& a_{1,1} z^{r(1,1)} & a_{1, k} z^{r(1, k)} & \ldots \\
b_{1,0} z^{r(1,0)} & a_{2,1} z^{r(2,1)} & a_{2, k} z^{r(2, k)} & \ldots \\
\ldots \ldots \ldots \ldots \ldots \ldots & \ldots \ldots \ldots \ldots \ldots & \ldots \ldots \\
b_{n-1,0} z^{r(n-1,0)} & a_{n, 1} z^{r(n, 1)} & a_{n, k} z^{r(n, k)} & \\
b_{n, 0} z^{r(n, 0)} & 1 & 1 & \ldots
\end{array}\right]
$$

The following two theorems shed some light on what happens in general.

THEOREM 7. The correspondence between a $C$-n-fraction and an $n$-tuple of formal power series has the following properties:

(a) To each n-tuple there corresponds a $C$-n-fraction.

(b) To each $C$-n-fraction without zeros, except those that arise from interruptions, there corresponds an n-tuple of formal power series in the following way:

(1) If the C-n-fraction terminates at index $k$, then

$$
f_{0}^{(j)}(z)=A_{k}^{(j)}(z) / A_{k}^{(0)}(z) \quad(1 \leqslant j \leqslant n),
$$

and the order in $z$ of the difference between these functions and the $m$-th approximant of the C-n-fraction is increasing in $m$, thus at least $O\left(z^{m+1}\right)$.

(2) If the $C$-n-fraction does not terminate, then

$$
f_{0}^{(j)}(z)-A_{k}^{(j)}(z) / A_{k}^{(0)}(z)=O\left(z^{\sigma(k)+1}\right) \quad(1 \leqslant j \leqslant n),
$$

with $\sigma(k)$ monotonically increasing, thus at least $\sigma(k) \geqslant k$.

(3) If the $C$-n-fraction for $f_{0}^{(1)}, \ldots, f_{0}^{(n)}$ has interruptions of total order $k$, then 
there exist at least $k$ linearly independent relations

$$
P_{0}(z)+P_{1}(z) f_{0}^{(1)}(z)+\ldots+P_{n}(z) f_{0}^{(n)}(z) \equiv 0,
$$

with polynomial coefficients.

THEOREM 8. Consider a C-n-fraction connected with an n-tuple of formal power series.

(A). The following statements are equivalent:

(a) The $C$-n-fraction terminates.

(b) The C-n-fraction has interruptions of total order $n$.

(c) There exist $n$ linearly independent relations with polynomial coefficients as in Theorem 7 (b), (3).

(d) The n-tuple of functions consists of $n$ rational functions.

B. If $1, f_{0}^{(1)}, \ldots, f_{0}^{(n)}$ are linearly independent over $\mathscr{C}[z]$, the $C$-n-fraction algorithm has no interruptions (and thus does not terminate).

Before turning towards convergence matters, first a diagram - in which also a special type of $C$ - $n$-fractions is introduced - and some examples (for detailed information the reader is referred to [26], [30], [31]). Introduce the following notations

$F_{n}$ : $n$-tuples of formal power series over $\mathscr{C}$;

$F_{n}^{\mathrm{reg}} \subset F_{n}: 1, f_{0}^{(1)}, \ldots, f_{0}^{(1)}$ are linearly independent over the polynomials over $\mathscr{C}$

$C_{n}$ : non-terminating $C$-n-fractions with all coefficients different from zero;

$C_{n}^{\text {reg }} \subset C_{n}: C$-n-fractions with $b_{\jmath, 0}=1, a_{j, k} \neq 0, r(j, k)=\min (n+1-j, k)$;

$\phi$ : the construction of a $C$ - $n$-fraction from an $n$-tuple of functions;

$\chi$ : the construction of an $n$-tuple of functions from a $C$ - $n$-fraction.

We then have the following inclusion and mapping relations:

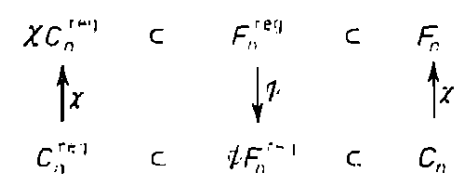

with $\left.\chi \phi\right|_{F_{n}^{\text {(reg) }}}=\left.\mathrm{id}\right|_{F_{n}^{\text {(reg) })}},\left.\phi \chi\right|_{C_{n}^{\text {(reg) }}}=\left.\mathrm{id}\right|_{C_{n}^{\text {(reg) }}}$.

An interesting question now surfaces immediately: does the absence of an interruption in the $C$-n-fraction algorithm automatically imply the absence of a dependency relation as introduced in Theorem 7 (c), (3)?

For the Euclidean algorithm for $n$ real numbers (the Jacobi-Perron algorithm) the answer is as follows (cf. [166]): $n=1:$ yes; $n=2:$ ?; $n \geqslant 3:$ no.

Choosing the construction method in the context of non-archimedean valuations and a special set of "integers" (replace the polynomials in $z$ by something a little different), the number of relations is always equal to the number of interruptions (cf. [165]). In the context of the straightforward 
generalisation of a $C$-fraction, however, we have for $C$ - $n$-fractions (cf. [31]):

$$
n=1: \text { yes (trivially); } n \geqslant 2: \text { no. }
$$

Some examples of these special $n$-tuples are given in the following theorem.

THEOREM 9. In the sequel we assume that $n$ is an integer with $n \geqslant 2$.

A. Let $g$ be the unique formal power series with constant term equal to 1 that satisfies

$$
\begin{gathered}
Y^{n}+(z-1) Y^{n-1}+z(z-2) Y^{n-2}+z^{2}(z-3) Y^{n-3}+\ldots \\
\ldots+z^{n-2}\{z-(n-1)\} Y+z^{n} \equiv 0,
\end{gathered}
$$

(with $a \in \mathscr{C} \backslash\{0\}, r \geqslant 1$ ) and define the n-tuple of functions as follows $f_{0}^{(n)}=g, \quad f_{0}^{(n+1-j)}=g^{j}-\left(g^{j-1}+z g^{j-2}+z^{2} g^{j-3}+\ldots+z^{j-2} g\right) \quad(2 \leqslant j \leqslant n)$, then we have

(1) There exists precisely one relation over the polynomials, given by

$$
\sum_{j=1}^{n} z^{j-1} f_{0}^{(j)}(z)+z^{n} \equiv 0 .
$$

(2) The C-n-fraction has the form

$$
\left[\begin{array}{cccc} 
& z^{n+1} & z^{n+1} & \cdots \\
-(n-1) z^{n-1} & -(n-1) z^{n-1} & -(n-1) z^{n-1} & \cdots \\
z^{n-2} & z^{n-2} & z^{n-2} & \\
\ldots \ldots & & & \cdots \\
z & z & z & \cdots \\
1 & 1 & 1 & \cdots
\end{array}\right]
$$
satisfies

B. If $f$ is the unique formal power series with constant term equal to 1 that

$$
Y^{k}-Y^{k-1}-a z^{r} \equiv 0 \quad(k \in \mathcal{N} \backslash\{1\}, r \in \mathcal{N}, a \in \mathscr{C} \backslash\{0\}),
$$

then the $n$-tuple $f, f^{2}, \ldots, f^{n}$ has a $C$-n-fraction with the properties:

(1) For $n=k-1$ there are no interruptions, nor does there exist a relation with polynomial coefficients for $1, f, f^{2}, \ldots, f^{\prime \prime}$.

(2) For $n \geqslant k$ there are interruptions with total order $n-k+1$ and there exist $n-k+1$ linearly independent relations with polynomial coefficients for $1, f$, $f^{2}, \ldots, f^{\prime \prime}$.

The form of the $C$-n-fraction is best described by giving the entries in an upwards slanting (under $45^{\circ}$ ) "diagonal" starting with the top-entry in the first column (which in (10) has second index 0). Thus the first "diagonal" has two entries, the second three and so on, till we reach the "diagonal" that starts at the bottom entry in the first column and which has $n+1$ entries, after that the "diagonals" all start on the bottomline of the array and have $n+1$ entries. 
(a) For $n=k-1$ the entries on "diagonal" number $j(1 \leqslant j \leqslant n-1)$ are the monomials that arise from expanding $\left(1+a z^{r}\right)^{j}$ using the bionomial theorem; after that they are the monomials that arise from expanding $\left(1+a z^{r}\right)^{k-1}$.

(b) For $n \geqslant k$ the entries on "diagonal" number $j(1 \leqslant j \leqslant n-1)$ are the monomials that arise from expanding $\left(1+a z^{r}\right)^{j} u$ sing the binomial theorem; after that they are the monomials that arise from expanding $\left(1+a z^{r}\right)^{k-1}$, supplemented by zeros.

There are, of course, other types of examples with $n$-tuples showing different behaviour - for many readers a matter of academic interest only maybe - and before looking into convergence just a final example.

Let $g$ be the unique formal power series with constant term equal to 1 that satisfies

$$
g^{2}-\left(1+2 \delta z^{\alpha}\right) g+2 \delta^{2} z^{2 \alpha} \equiv 0 \quad(\alpha \in \mathscr{N}, \delta \in \mathscr{C} \backslash\{0\}),
$$

and define the functions $f_{0}^{(1)}, f_{0}^{(2)}, f_{0}^{(3)}$ by

$$
f_{0}^{(1)}=1+\frac{a z^{\beta}}{g} \quad(\beta \in \mathcal{N}, a \in \mathscr{C} \backslash\{0\}), f_{0}^{(2)}=\left(f_{0}^{(1)}\right)^{2}, f_{0}^{(3)}=\left(f_{0}^{(1)}\right)^{3}
$$

Then there are two linearly independent relations with polynomial coefficients for $1, f_{0}^{(1)}, f_{0}^{(2)}, f_{0}^{(3)}$ and the $C$-3-fraction for $f_{0}^{(1)}, f_{0}^{(2)}, f_{0}^{(3)}$ has no interruptions and is of the form:

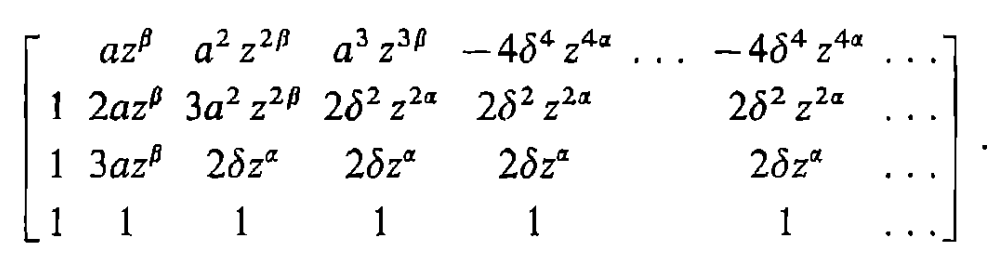

For the remaining part of this section, we will consider $C$ - $n$-fractions that show the same "minimal"-degree behaviour as regular $C$ - $n$-fractions (i.e. elements of $C_{n}^{\text {reg }}$ ), but where only the top-and bottom-line in the array (10) have to be defferent from zero:

$$
\begin{gathered}
r(j, 0)=0 \quad(1 \leqslant j \leqslant n), \quad r(j, k)=\min (n+1-j, k) \quad(1 \leqslant j \leqslant n, k \geqslant 1), \\
b_{j, 0} \neq 0 \quad(1 \leqslant j \leqslant n), \quad b_{k} \neq 0, \quad a_{1, k} \neq 0 \quad(k \geqslant 1) .
\end{gathered}
$$

Furthermore we need a special real number $\varrho=\varrho_{n}$ defined by

$$
\varrho^{n}+2^{-1} \varrho^{n-1}+2^{-2} \varrho^{n-2}+\ldots+2^{-n+1} \varrho-2^{-n-1} \equiv 0, \quad 1 / 6<\varrho \leqslant 1 / 4
$$

(simple analysis shows that $\varrho_{1}=1 / 4, \varrho_{n}$ monotonically decreasing, $\varrho_{n} \rightarrow 1 / 6$ for $n \rightarrow \infty$.)

Then we have the following convergence results:

THEOREM 10. Let $\left(\left\{A_{k}^{(j)}(z) / A_{k}^{(0)}(z), 1 \leqslant j \leqslant n\right\}, k \geqslant 0\right)$ be the approximant $n$-tuples of a $C$-n-fraction satisfying (15), moreover

$$
a_{j}=\sup _{k \geqslant 2}\left|a_{j, k}\right|<\infty \quad(1 \leqslant j \leqslant n) .
$$


Then the $n$ sequences converge to an n-tuple of analytic functions, uniformly in $z$ on each compact subset of

$$
\mathscr{D}=\left\{z \in \mathscr{C}:|z|<\varrho_{n} \cdot \min _{1 \leqslant j \leqslant n} a_{j}^{-1 /(n+1-j)}\right\} .
$$

$\left(a_{j}=0\right.$ : omit this term from the minimum.)

THEOREM 11. Consider a C-n-fraction as in Theorem 10 with

$$
a_{j}=\limsup _{k \rightarrow \infty}\left|a_{j, k}\right|<\infty \quad(1 \leqslant j \leqslant n) .
$$

Then the $n$ sequences converge to an $n$-tuple of functions which are meromorphic. on $\mathscr{D}$ from (17), uniformly in $z$ on each compact subset of $\mathscr{D}$. In the poles of the limit functions, the $C$-n-fraction shows a very special divergence behaviour, i.e. there exists at least one value $r, 1 \leqslant r \leqslant n$, such that

$$
\lim _{k \rightarrow \infty} A_{k}^{(0)}(z) / A_{k}^{(r)}\left(z_{0}\right)=0, \quad \lim _{k \rightarrow \infty} A_{k}^{(j)}(z) / A_{k}^{(r)}\left(z_{0}\right) \text { exists for } j \neq r \quad(1 \leqslant j \leqslant n) .
$$

Theorem 12. Consider the situation of Theorem 10 and let

$$
\lim _{k \rightarrow \infty} A_{k}^{(j)}(z) / A_{k}^{(0)}(z)=g_{j}(z) \quad(1 \leqslant j \leqslant n) \text { on } \mathscr{D} \text {. }
$$

Then the functions $g_{1}, \ldots, g_{n}$ are analytic on $\mathscr{D}$, together with the function 1 linearly independent over the polynomials and if we apply the construction $\chi$ on the $C$-n-fraction (i.e. we derive the n-tuple of formal power series that shows agreement in order as described before) then the Maclaurin series of the functions $g_{1}, \ldots, g_{n}$ are recovered.

THEOREM 13. Consider the situation of Theorem 11 and let

$$
\lim _{k \rightarrow \infty} A_{k}^{(j)}(z) / A_{k}^{(0)}(z)=g_{j}(z) \quad(1 \leqslant j \leqslant n) \text { on } \mathscr{D} \text {, except for the singularities. }
$$

Then the functions $g_{1}, \ldots, g_{n}$ are meromorphic on $\mathscr{D}$, analytic at the origin, together with the function 1 linearly independent over the polynomials. Moreover, if we apply the construction $\chi$ on the $C$-n-fraction (i.e. we derive the n-tuple of formal power series $f_{1}, \ldots, f_{n}$ that shows agreement in order as described before) and if $\mathscr{E}$ is the domain of meromorphy of these formal power series, then $\mathscr{D} \subset \mathscr{E}$ and $f_{j} \equiv g_{j}(1 \leqslant j \leqslant n)$ on $\mathscr{D}$.

Remark. For $n=1$ we recover from Theorems 12 and 13 old results due to E. B. van Vleck [191] and A. Pringsheim [172]. Exploiting the connection between certain walks in the Padé-n-table and $C$ - $n$-fractions, it is possible to derive convergence results for sequences of simultaneous rational approximants. In the case that we do not have a $C$-n-fraction, but some other form of the coefficients for the recurrence relation, convergence theorems better suited for that situation can easily be given; after some examples connected 
with the previous theorems, one of these will be given (dealing with so-called "limitperiodic $n$-fractions").

EXAmple. A. Consider the pair of functions $f_{1}(z)=(1-z)^{1 / 2}$, $f_{2}(z)=(1-z)^{1 / 4}$. They give rise to a regular $C$-2-fraction with coefficients

$$
\begin{aligned}
b_{1,0} & =b_{2,0}=1, \\
a_{1,1} & =1, \\
a_{1,3 k+1} & =\frac{(k+1 / 2)(k+1 / 4)}{(3 k-1) \cdot 3 k \cdot(3 k+1)} \quad(k \geqslant 1), \\
a_{1,2} & =1 / 8 \\
a_{1,3 k+2} & =\frac{(k+1 / 2)(k+1 / 4)}{3 k \cdot(3 k+1) \cdot(3 k+2)} \quad(k \geqslant 1), \\
a_{1,3 k+3} & =\frac{(k+1 / 2)(k+3 / 4)(k+1)}{(3 k+1) \cdot(3 k+2) \cdot(3 k+3)} \quad(k \geqslant 0), \\
a_{2,1} & =1, \\
a_{2,3 k+1} & =-\frac{3 k+3 / 4}{3(3 k+1)} \quad(k \geqslant 1), \\
a_{2,2} & =-1 / 4, \quad(k \geqslant 1), \\
a_{2,3 k+2} & =-\frac{3 k^{2}+9 k / 4+1 / 2}{(3 k+1)(3 k+2)} \quad(k \geqslant 0) . \\
a_{2,3 k+3} & =-\frac{k+1}{(3 k+2)} \quad(k+1)
\end{aligned}
$$

Thus $a_{1}=1 / 27, a_{2}=1 / 3$ and $\mathscr{D}=\{z \in \mathscr{C}:|z| \leqslant 3(3 \sqrt{3}-1) / 4\}$; the radius is approximately 0.549 , still "far away" from the expected unit disk.

B. Let $n$ real numbers be given: $\alpha_{1}, \ldots, \alpha_{n} \in \mathscr{R}^{+} \backslash\{1, \ldots, n-1\}$. Introduce real numbers $B_{k}\left(\beta_{1}, \ldots, \beta_{n}\right)$ by

$$
\prod_{j=1}^{n}\left(z+\beta_{1}\right)-\prod_{j=1}^{n} \beta_{j}=\sum_{k=1}^{n} B_{k}\left(\beta_{1}^{-}, \ldots, \beta_{n}\right)(z-k+1)_{k} .
$$

Again the ascending factorial is used: $(z-k+1)_{k}=(z-k+1) \ldots(z-1) z$. Introduce the following $n$-tuple of combinations of quotients of hypergeometric functions

$$
\begin{aligned}
f^{(n-j)}(z)= & \sum_{k=j}^{n} \frac{B_{k}\left(\alpha_{1}-j, \ldots, \alpha_{n}-j\right)}{\prod_{i=1}^{n}\left(\alpha_{i}-j\right)_{k+1}} z^{k-1} \frac{{ }_{0} F_{n}\left(\alpha_{1}+k-j+1, \ldots, \alpha_{n}+k-j+1 ; z\right)}{{ }_{0} F_{n}\left(\alpha_{1}+1, \ldots, \alpha_{n}+1 ; z\right)} \\
f^{(n)}(z) & =-\frac{{ }_{0} F_{n}\left(\alpha_{1}, \ldots, \alpha_{n} ; z\right)}{{ }_{0} F_{n}\left(\alpha_{1}+1, \ldots, \alpha_{n}+1 ; z\right)} .
\end{aligned}
$$


Then this $n$-tuple has a regular $C$ - $n$-fraction with coefficients

$$
\begin{aligned}
b_{n-k, 0} & =\frac{B_{j}\left(\alpha_{1}-j, \ldots, \alpha_{n}-j\right)}{\prod_{i=1}^{n}\left(\alpha_{i}-j\right)_{k+1}} \quad(1 \leqslant j \leqslant n-1), b_{n, 0}=1, \\
a_{n+1-j, k} & =\frac{B_{j}\left(\alpha_{1}+k-j, \ldots, \alpha_{n}+k-j\right)}{\prod_{i=1}^{n}\left(\alpha_{i}+k-j\right)_{k+1}} \quad(1 \leqslant j \leqslant n, k \geqslant 1) .
\end{aligned}
$$

As $a_{j}=0(1 \leqslant j \leqslant n)$, the $C$ - $n$-fraction converges to an $n$-tuple of functions, meromorphic on $\mathscr{C}$ and analytic at the origin.

As a final contribution to the theorems concerning convergence, we turn to the subject of modification of a generalised continued fraction (cf. [40], [41], [118]).

THEOREM 14. Let the coefficients of an $n$-fraction be given by

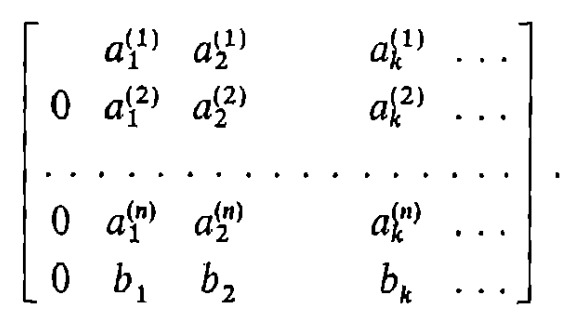

Assume that this $n$-fraction is limit-periodic, i.e.

$$
\lim _{k \rightarrow \infty} a_{k}^{(j)}=a^{(j)} \quad(1 \leqslant j \leqslant n), \quad \lim _{k \rightarrow \infty} b_{k}=b,
$$

and that the zeros $z_{1}, \ldots, z_{n+1}$ of the "auxiliary equation"

$$
z^{n+1}=b z^{n}+a^{(n)} z^{n-1}+\ldots+a^{(2)} z+a^{(1)}
$$

are simple and ordered by the value of their index: $\left|z_{1}\right|>\left|z_{2}\right|>\ldots>\left|z_{n+1}\right|$.

Then the following holds.

A. The n-fraction converges in $\hat{\mathscr{C}}^{n}=(\mathscr{C} \cup\{\infty\})^{n}$.

B. If all limits are finite - say $\xi_{0}^{(1)}, \ldots, \xi_{0}^{(1)}$ - and moreover $\left|z_{n+1}\right|>0$, then all the tails of the $n$-fraction converge to finite limits also, say

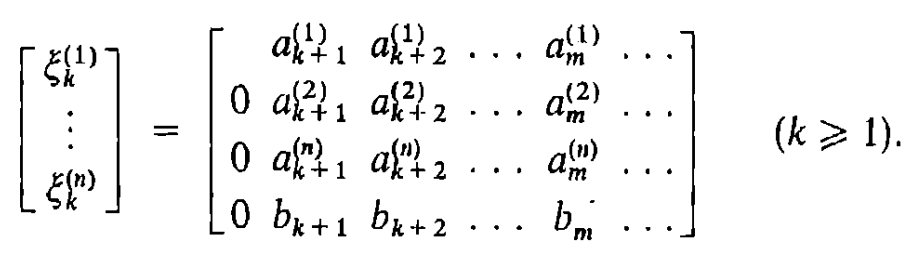

Furthermore, the sequences of tail-values also converge

$\lim _{k \rightarrow \infty} \xi_{k}^{(j)}=w^{(j)} \quad(1 \leqslant j \leqslant n)$, where $w^{(1)}=\frac{a^{(1)}}{z_{1}}, w^{(j)}=\frac{a^{(j)}+w^{(j-1)}}{z_{1}} \quad(1 \leqslant j \leqslant n)$. 
Finally, it can be shown that the introduction of these tail-limits into the method of consecutive linear fractional transformations to calculate the approximants of the n-fraction, leads to convergence acceleration. To be more precise, introduce for $k \geqslant 1$ :

$$
\begin{aligned}
& s_{k}^{(1)}\left(y_{1}, \ldots, y_{n}\right)=\frac{a_{k}^{(1)}}{b_{k}+y_{n}} \\
& s_{k}^{(f)}\left(y_{1}, \ldots, y_{n}\right)=\frac{a_{k}^{(j)}+y_{j-1}}{b_{k}+y_{n}} \quad(2 \leqslant j \leqslant n),
\end{aligned}
$$

and for $1 \leqslant j \leqslant n, k \geqslant 1$ the iterated Möbius-transformations:

$\mathscr{S}_{1}^{(j)}\left(y_{1}, \ldots, y_{n}\right)^{\prime}=s_{1}^{(l)}\left(y_{1}, \ldots, y_{n}\right)$,

$\mathscr{P}_{k}^{(j)}\left(y_{1}, \ldots, y_{n}\right)=\mathscr{P}_{k-1}^{(j)}\left(s_{k}^{(1)}\left(y_{1}, \ldots, y_{n}\right), \ldots, s_{k}^{(n)}\left(y_{1}, \ldots, y_{n}\right)\right) \quad(k \geqslant 2)$

Then the approximant $n$-tuples satisfy

$$
\mathscr{S}_{k}^{(I)}(0, \ldots, 0)=\frac{A_{k}^{(n)}}{A_{k}^{(0)}},
$$

and moreover, the convergence acceleration is shown by:

$$
\lim _{k \rightarrow \infty} \frac{\xi^{(n)}-\mathscr{S}_{k}^{())}\left(w^{(1)}, \ldots, w^{(n)}\right)}{\xi^{(1)}-\mathscr{S}_{k}^{(1)}(0, \ldots, 0)}=0 .
$$

It would take too much time to go into details here, the procedure is straightforward. Consider an $n$-fraction where the coefficients are functions of a complex variable $z$.

Then take for instance the following steps

- check the limit-periodicity,

- check the auxiliary equation,

- the condition of simple zeros, ordered as in the theorem, leads to conditions on $z$,

- check the convergence to finite limits, using Theorem 6,

- translate the conditions on $z$ into a domain (?) in $\mathscr{C}$.

\section{Convergence in the Padé-n-table}

It is out of the question to treat all known convergence results here, therefore we will restrict ourselves mainly to the list of (semi)-normal tables given in Theorem 2 , along with information on several "more general" results.

(a) the exponential function system $\left(e^{\lambda_{j} z}, 1 \leqslant j \leqslant n\right)$ with $\lambda_{j} \neq 0, \lambda_{j} \neq \lambda_{i}$.

Convergence to the $n$-tuple of functions for any sequence $\left(\varrho_{0}(k), \varrho_{1}(k), \ldots\right.$ $\left.\ldots, \varrho_{n}(k)\right)$ with $\sigma(k)=\varrho_{0}(k)+\varrho_{1}(k)+\ldots+\varrho_{n}(k) \rightarrow \infty$ for $k \rightarrow \infty$. Note that there is no monotonicity condition on the order of approximation. If $\sigma(k) \rightarrow \infty$ and $\varrho_{j} / \varrho_{0} \rightarrow \omega_{j}(1 \leqslant j \leqslant n)$ for $k \rightarrow \infty$, then the denominators and numerators 
converge seperately. All convergence results are uniform on compact subsets of $\mathscr{C}$ (cf. J. Mall, A. J. Goddijn, A. I. Aptekarev).

(b) the binomial function system $\left((1-z)^{\lambda_{j}}, 1 \leqslant j \leqslant n\right)$ with $\lambda_{j} \notin \mathscr{Z}$, $\lambda_{j}-\lambda_{i} \notin \mathscr{Z}$.

Convergence for $\varrho_{0} \rightarrow \infty, \varrho_{j}$ fixed $(1 \leqslant j \leqslant n)$ on $|z|<1$ (cf. A. J. Goddijn).

(c) Angelesco-systems.

Convergence results by a.o. V. A. Kalyagin, E. M. Nikishin, V. N. Sorokin.

(e) the hypergeometric function system $\left({ }_{1} F_{1}\left(1 ; c_{j} ; z\right), \quad 1 \leqslant j \leqslant n\right)$, $c_{j} \notin \mathscr{Z} \backslash{ }_{v} \mathcal{N}, c_{i}-c_{j} \notin \mathscr{Z}$.

Convergence to the $n$-tuple of functions for any sequence $\left(\varrho_{0}(k)\right.$, $\left.\varrho_{1}(k), \ldots, \varrho_{n}(k)\right)$ with $\sigma(k)=\varrho_{0}(k)+\varrho_{1}(k)+\ldots+\varrho_{n}(k) \rightarrow \infty$ for $k \rightarrow \infty$. Note that there is no monotonicity condition on the order of approximation. If $\sigma(k) \rightarrow \infty$ and $\varrho_{j} / \varrho_{0} \rightarrow \omega_{j}(1 \leqslant j \leqslant n)$ for $k \rightarrow \infty$, then the denominators and numerators converge seperately. All convergence results are subject to the condition $\varrho_{0} \geqslant \varrho_{j}-1(1 \leqslant j \leqslant n)$, and uniform on compact subsets of $\mathscr{C}$; no monotonicity condition (cf. M. G. de Bruin).

(e) the hypergeometric function system $\left({ }_{1} F_{1}\left(1 ; c ; \lambda_{j} z\right), 1 \leqslant j \leqslant n\right)$ with $\lambda_{j} \neq 0, \lambda_{j} \neq \lambda_{i}$.

Convergence to the $n$-tuple of functions for any sequence $\left(\varrho_{0}(k), \varrho_{1}(k), \ldots, \varrho_{n}(k)\right)$ with $\sigma(k)=\varrho_{0}(k)+\varrho_{1}(k)+\ldots+\varrho_{n}(k) \rightarrow \infty$ for $k \rightarrow \infty$, subject to the condition $\varrho_{0} \geqslant \varrho_{j}-1 \quad(1 \leqslant j \leqslant n)$. Note that there is no monotonicity condition on the order of approximation (cf. A. I. Aptekarev).

(f) de Montessus de Ballore-type theorems.

Results by a.o. J. Mall, P. R. Graves-Morris and E. B. Saff, A. A. Gonchar and E. A. Rakhmanov, J. van Iseghem, C. H. Lutterodt, J. Karlsson and H. Wallin.

(g) diagonal/“near" diagonal sequences under general conditions (capacity-results etc.).

Papers by A. A. Gonchar and E. A. Rakhmanov, V. A. Kalyagin, E. M. Nikishin, J. Nuttall, H. Stahl.

From the literature it appears that there are several methods to prove convergence in the Padé-n-table:

1. Using asymptotics for the determinants in the explicit forms for the denominators and remainders.

2. Using potential theory and the theory of (generalised) orthogonal polynomials.

3. Using explicil calculation and estimation for denominators and remainder.

4. Using the connection with generalised continued fractions for certain sequences of approximants.

It must be noted, however, that the convergence problem is very difficult, but progress is made in several directions. 


\section{Concluding remarks}

The number of applications of simultaneous rational approximation with common denominator is steadily growing. In this connection the work on time-series (M. Hallin), vector Padé approximants (P. R. Graves-Morris, J. M. Wilkins, J. van Iseghem) must be mentioned. Furthermore applications to "two-point approximation" and "partial Padé approximation" ([39]) are being studied at the moment. The last mentioned application shows great potential for improvement of numerical approximation. Here information on eventual singularities and/or zeros of the functions is used to first "force" a similar behaviour on the rational approximants by prescribing factors in numerator and/or denominator and then imposing conditions on the order of approximation.

. We consider the pair of functions

$$
\begin{aligned}
& f_{1}(t)=\frac{\exp t}{1-2 t}=1+3 t+\frac{13}{2} t^{2}+\frac{79}{6} t^{3}+\ldots \\
& f_{2}(t)=(1-t)^{3 / 2}=1-\frac{3}{2} t+\frac{3}{8} t^{2}+\frac{1}{16} t^{3}+\ldots
\end{aligned}
$$

In order to imitate both the pole at $t=0.5$ and the limiting value 0 when approaching $t=1.0$ from below along the real axis - we introduce the polynomials

$$
v_{1}(t)=1, \quad v_{2}(t)=(t-1)(t-2), \quad w(t)=t-2,
$$

which leads for instance to the approximation problem (for details on the degree restrictions cf. [39])

$$
\tilde{p}_{j}(t) \tilde{v}_{j}(t)-\tilde{q}(t) \tilde{w}(t) f_{j}(t)=O\left(t^{3}\right) \quad(j=1,2)
$$

where the approximants we want to calculate are nothing else but $\tilde{p}_{j}(t) \tilde{v}_{j}(t) / \tilde{q}(t) \tilde{w}(t)$. Dividing out the auxiliary polynomials, the problem reduces to

$$
\tilde{p}_{1}(t)-\tilde{q}(t) \exp (t)=O\left(t^{3}\right), \quad \tilde{p}_{2}(t)-\tilde{q}(t) \sqrt{1-t}=O\left(t^{3}\right) .
$$

Calculating the approximants we find

$$
\begin{gathered}
\tilde{p}_{1}(t) \tilde{v}_{1}(t) / \tilde{q}(t) \tilde{w}(t)=\left(1+\frac{7}{12} t\right) /\left(\left(1-\frac{5}{12} t-\frac{1}{12} t^{2}\right)(1-2 t)\right), \\
\tilde{p}_{2}(t) \tilde{v}_{2}(t) / \tilde{q}(t) \tilde{w}(t)=\left(1-\frac{11}{12} t\right)(1-t) /\left(1-\frac{5}{12} t-\frac{1}{12} t^{2}\right) .
\end{gathered}
$$

The approximants to $f_{j}$ have simple poles at $t=(-5 \pm \sqrt{73}) / 2$, i.e. at $t=1.772$ and $t=-6.772$, moreover the approximant to $f_{1}$ also has a simple pole at $t=0.5$, while that to $f_{2}$ has a zero at $t=1.0$. We compare this with the $(0,1,1)$ system of German polynomials for $\left\{f_{1}, f_{2}\right\}$; we find

$$
\begin{gathered}
P_{1}(0,1,1 ; t)=1+\frac{59}{36} t, \quad P_{2}(0,1,1 ; t)=1-\frac{103}{36} t \\
P_{0}(0,1,1 ; t)=1-\frac{49}{36} t-\frac{29}{12} t^{2}
\end{gathered}
$$


M. G. de BRUIN

The $(0,1,1)$ approximants have both the same simple poles at $t=(-49$ $\pm \sqrt{14929}) / 174$, i.e. at $t=-0.983$ and $t=0.421$. Plotting the Euclidean distance in 2-space between the pair of functions and their pair of approximants, the partial Padé approximants show a superior numerical behaviour. This will be a matter of continuing research.

\section{References}

[1] A. Angclesco, Sur une classe de polynômes à une variable, C. R. Acad. Sci. Paris 162 (1916) 121-123.

[2] -, Sur l'approximation simultanée de plusieurs intégrales définies, C. R. Acad. Sci. Paris 167 (1918), 629-631.

[3] -, Sur deux extensions des fractions continues algébriques, C. R. Acad. Sci. Paris 168 (1919), 262-265.

[4] -, Sur certains polynômes orthogonaux, C. R. Acad. Sci. Paris 176 (1923) 1282-1284.

[5] A. I. Aptekarev (А. И. А п т е к а р в), О сходимости рачиолалыьых аппроксимачий к набору экспонент, Вестник Моск. ун-та матем. механ. (1) 1981, 68-74 (= Convergence of rational approximations to a set of exponents, Moscow Univ. Math. Bull. 36 (1) (1981), 81-86).

[6] -, Об аппроксимачиях Паде к иабору $\left\{{ }_{1} F_{1}\left(1, c, \lambda_{i} z\right) ; 1 \leqslant i \leqslant k\right\}$, Вестник Моск. ун-та матем. механ. (2) $1981,58-62$ (= Padé approximation for the system $\left\{_{1} F_{1}\left(1, c, \lambda_{i} z\right)\right.$; $1 \leqslant i \leqslant k\}$, Moscow Univ, Math. Bull. 36 (2) (1981), 73-76).

[7] -, Аналитические свойства функций, представимых 2-мерными пепрерызными дроблми с постоянными коэффичиентами и их совместные аппроксимачии Паде-Эрмита (тип II), Институт Прнкладной Математики им. М. В. Келдыша АН СССР, препринт 79, Москва 1985.

[8] A. I. Aptekarev, V. A. Kalyagin, Analytic properties of two-dimensional P-fraction expansions with periodical coefficients and their simultaneous Padé-Hermite approximants, in Rational Approximaton and its Application in Mathematics and Physics, Lańcut 1985, J. Gilewicz, M. Pindor and W. Siemaszko, Eds., Lecture Notes in Math. 1237, Springer, Berlin 1987, 145-160.

[9] R. J. Arms, A. Edrei, The Padé table and continued fractions generated by totally positive sequences, in Mathematical Essayes Dedicated to A. J. Macintyre, Olio University Press Athens, Ohio, 1970, 1-21.

[10] P. Bachman n, Zur Theorie von Jacobi's Kettenbruch Algorithmen, J. Reine Angew. Math. 75 (1873), 25-34.

[11] A. Baker, A note on the Padé table, Proc. Kon. Akad. v. Wet. A'dam Ser. A $69=$ Indag. Math. 28 (1966), 596-601.

[12] G. A. Baker jr., Analytic continuation beyond the first Riemann sheet, in Rational Approximation and Interpolation, P. R. Graves-M orris, E. B. Sa Ir and R. S. Varga, Eds., Lecture Notes in Math. 1105, Springer, New York 1984, 285-294.

[13] G. A. Baker jr., D. S. Lubinsky, Convergence theorems for rows of differential and algebraic Hermite-Padé approximants, J. Comput. Appl. Math. 18 (1987), 29-52.

[14] L. Bernstein, The Jacobi-Perron Algorithm, Its Theory and Applications, Lecture Noles in Math. 207, Springer, Berlin 1972.

[15] F. Beukers, Padé approximation in number theory, in Padé Approximation and Its Applications, Amsterdam 1980, M. G. de Bruin and H. van R ossum, Eds., Lecture Notes in Math. 888 Springer, Berlin 1981, 90-99.

[16] D. I. Bodnar, (Д. И. Боднар) Ветвяциеся чеплье ороби, Киен 1986.

[17] P. I. Bodnarchuk, (П. И. Боднарчук), see the references in 181. 
[18] P. B. Borwein, Quadratic and higher order Padé approximants, Colloq. Math. Soc. János Bolyai 49 (1985), 213-224.

[19] -, Quadratic Hermite-Padé approximation to the exponential function, Constr. Approx. 2 (1986), 291-302.

[20] -, Padé approximants to q-elementary functions, Constr. Approx., 4 (1988), 391-402.

[21] A. J. Brentjes, Multi-dimensional continued fraction algorithms, in Number Theory and Computer's, Center for Mathematics and Informatics, Amsterdam 1980.

[22] -, Multi-dimensional continued fraction algorithms, Thesis, Leiden 1981.

[23] C. Brezinski, Padé-type approximation and general orthogonal polynomials, ISNM, Vol. 50, Brikhäuser, Basel 1980.

[24] -, On interpolatory multivariate Padé type approximants, BIT 26 (1986), 254-258.

[25] -, Partial Padé Approximants, ANO-167, Univ. des Sciences et Techn. de Lille Flandres-Artois 1986, J.A.T. 54 (1988), 210-233.

[26] M. G. de Bruin, Generalized C-fractions and a multidimensional Padé table, Thesis, Univ. of Amsterdam 1974.

[27] -, Convergence in the Padé table for ${ }_{1} F_{1}(1 ; c ; x)$, Proc. Kon. Akad. v. Wet. A'dam Ser, A $79=$ Indag. Math. 38 (1976), 408-418.

[28] -, Three new examples of generalized Padé tables which are partly normal, Dept. of Math., Univ. of Amsterdam, report 76-11, Amsterdam 1976.

[29] - Convergence along steplines in a generalized Padé table, in Padé and Rational Approximation, E. B. Saff and R. S. Varga, Eds., Acad. Press, New York 1977, 15- 22.

[30] -, Convergence of generalized C-fractions, J, Approx. Th. 24 (1978), 177-207.

[31] -, The interruption phenomenon for generalized continued fractions, Bull. Austral. Math. Soc. 19 (1978), 245-272.

[32] -, Convergence of some generalized continued fractions, Dept. of Math., Univ. of Amsterdam, report 79-05, Amsterdan 1979.

[33] -, Generalized Padé tables and some algorithms therein, in Proc. of the First French-Polish Meeting on Padé Approximation and Convergence Acceleration Techniques, Warsaw 1981, J. Gilewicz, Ed., CPT-81/PE 1354, CNRS, Marseille 1982.

[34] -, New convergence results for continued fractions generated by four-term recurrence relations, J. Comput. Appl. Math. 9 (1983), 271-278.

[35] -, Some convergence results in simultaneous rational approximation to the set of hypergeometric functions $\left\{F_{1}\left(1 ; c_{i} ; z\right), 1 \leqslant i \leqslant n\right\}$, in Padé Approximation and Its Applications, Bad Honnef 1983, H. Werner and H.-J. Bünger, Eds., Lecture Notes in Math. 1071 Springer, Berlin 1984, 12-33.

[36] -, Some explicit formulae in simultaneous Padé approximation, Linear Algebra Appl. 63 (1984), 271-281.

[37] -, Simultaneous Padé approximation and orthogonality, in Polynomes Orthogonaux et Applications, Bar-Le-Duc 1984, C. B rezinski, A. Draux, A. P. Magnus, P. Maroni and A. Ronveaux, Eds., Lecture Notes in Math. 1171 Springer, Berlin 1985, 74-83.

[38] -, Simultaneous rational approximation to some q-hyperyeometric functions, in Nonlinear Numerical Melhods and Rational Approximation, A. Cuy t, Ed., D. Reidel, Dordrecht 1988, $135-142$.

[39] -, Simultaneous partial Padé approximants, J. Comput. Appl. Math. 21 (1988), 343-355.

[40] M. G. de Bruin, L. J a c o b s e $\mathrm{n}$, The dominance concept for linear recurrence relations with applications to continued fractions, Neuw. Arch. Wisk. (4) 3 (1985), 253-266.

[41] -, -, Modification of generalised continued fractions I: Definition and application to the limit-periodic case, in Rational Approximaton and Its Application in Mathemaltics and Physics, Eanicut 1985, J. Gilewicz, M. Pindor and W. Siemaszko, Eds., Lecture Notes in Math. 1237, Springer, Berlin 1987, 161-176.

[42] V. Brun, En generalisation av kjedebriken $I, I I$, Skr. Vidensk. Selsk. Kristiania 1919 nr. 6, $1920 \mathrm{nr} .6$ (mat. nat. kl.). 
[43] -, Mehrdimensionale Algorithmen welche die Eulersche Kettenbruchentwicklung der Zahl everallgemeinern, Sammelband zu Ehren Eulers 250. Geburtstages, Akad. Verlag, Berlin 1959, $87-100$.

[44] S. K. Bu rley, S. O. Joh n, J. Nuttall, Vector orthogonal polynomials, SIAM J. Numer. Anal. 18 (1981), 919-924.

[45] Cl. Chaffy, Une construction "homogène" d'approximant de Padé à deux variables complexes, Numer. Math. 45 (1984), 149-164.

[46] J. S. R. Chish ol m, Rational approximants defined from double power series, Math. Comp. 27 (1973), 84L-848.

[47] -, Generalisations of Padé approximants, Circuits, Systems, Signal Processing 1 (1982), 279-287.

[48] J. S. R. Chisholm, P. R. Graves-Morris, Generalisation of the theorem of de Montessus to two variable approximants, Proc. Roy. Soc. London Ser. A 342 (1975), 341-372.

[49] J. S. R. Chisholm, R. Hugh Jones, Relative scale covariance of n-variable approximants, Math. Inst. Univ. of Kent, Canterbury, preprint 1974.

[50] J. S. R. Chisbolm, J. McEwan, Rational approximants defined from power series in $N$ variables, Proc. Roy. Soc. London Ser. A 336 (1974), 421-452.

[51] D. V. Chu d no vsky, Riemamn monodromy problem, isomonodromy deformation equations and completely integrable systems, in Bifurcation Phenomena in Mathematical Physics and Related Problems, C. Bardos and D. Bessis, Eds., Reidel, Dordrecht 1980, 385-447.

[52] D. V. Chudnovsky, G. V. Chudnovsky, Multidimensional Hermite interpolation and Padé approximation, in The Riemann Problem, Complete Integrability and Arithmetic Applications IHES/Columbia University 1979-1980, D. V. Chudnovsky and G. V. Chudnovsky, Eds., Lecture Notes in Math. 925, Springer, New York 1982, 271-298.

[53] -, -, Bäcklund transformations for linear differential equations and Padé approximations I, J. Math. Pures Appl. (9) 61 (1982), 1-16.

[54] -, -, Pade and ralional approximations to systems of functions and their arithmetic applications, in Number Theory, D. V. Cluudnovsky, G. V. Chudnovsky, H. Cohn and M. Natansion, Eds., Lecture Notes in Math. 1052, Springer, New York 1984, 37-84.

[55] -, -, Padé approximations to solutions of linear differential equations and applications to diophantine analysis, in Number Theory, D. V. Chudnovsky, G. V. Chudnovsky, H. Cohn and M. Natanson, Eds., Lecture Notes in Math. 1052, Springer, New York 1984, $85-167$.

[56] -, -, Applications of Padé approximations to diophantine inequalities in values of G-functions, in Number Theory, D. V. Chudnovsky, G. V. Chudnovsky, H. Cohn and M. Nat a n s o n, Eds., Lecture Notes in Math. 1135, Springer, New York 1985, 9-51.

[57] -, -, Applications of Padé approximations to the Grothendieck conjecture on linear differential equations, in Number Theory. D. V. Chudnovsky, G. V. Chudnovsky, H. Cohn and M. Nata ns on, Eds., Lecture Notes in Math. 1135, Springer, New York 1985, 52-100.

[58] -, -, Computer assisted number theory, in Number Theory, D. V. Chudnovsky, G. V. Chudnovsky, H. Cohn and M. Nalanson, Eds., Lecture Notes in Math. 1240, Springer, New York 1987, 1-68.

[59] G. V. Chudnovsky, Padé approximants to the generalized hypergeometric: functions $I$, J. Math. Pures Appl. (9) 58 (1979), 445-476.

[60] -, Rational and Padé approximants to solutions of linear differential cequations and the monodromy theory, Lecture Notes in Phys. 126, Springer, Berlin 1980, 136-169.

[61] -, Padé approximation and the Riemann monodromy problem, in Bifurcation Phenomena in Mathematical Physics and Related Topics, C. Bardos and D. Bessis, Eds., Reidel, Dordrecht 1980, 449-510.

[62] -, Orthogonal polynomials, Pudé approximants and applications to transcendental numbers, 86th annual meeting of the AMS, San Antonio 1980. 
[63] J. Coates, On the algebraic approximation of functions $I-I I I$ and $I V$, Proc. Kon. Akad, v. Wet. A'dam Ser. A 69 and $70=$ Indag. Math. 28 (1966), 421-461 and 29 (1967), 205--212.

[64] P. van der Cruyssen, Linear difference equations and generalized concinued fractions, Computing 22 (1979), 269-278.

[65] -, A continued fraction algoritim, Numer. Math. 37 (1981) 149-156.

[66] - Stable evaluation of generalized continued fractions, SIAM J. Numer. Anal. 18 (1981), $871-881$.

[67] -, Convergence of generalized continued fractions, Internat. J. Comput. Math. 10 (1982), 295-310.

[68] A. M. Cuyt, The $Q D$ algorithm and multivariate Padé approximation, Numer. Math. 42 (1983), 259-269.

[69] -, Abstract Padé Approximants for Operators; Theory and Applications, Lecture Notes in Math. 1065, Springer, Berlin 1984.

[70] -, A de Montessus de Ballore theorem for mutivariate Padé approximants, J. Approx. Theory 43 (1985), 43-52.

[71] -, A review of multivariate Padé approximation theory, J. Comput. Appl. Math. 12/13 (1985), $221-232$.

[72] -, General Order Multivariate Rational Hermite Interpolants, Dept. of Math., Univ, of Antwerp, Antwerpen 1986.

[73] -, Singular rules for the calculation of non-normal multivariate Padé approximants, J. Comput. Appl. Math. 14 (1986), 289-301.

[74] A. M. Cuyt, B. M. Verdonk, General order Newton-Padé approximants for multivariate functions, Numer. Math. 43 (1984), 293-307.

[75] A. M. Cuyt, H. Werner, L. Wuytack, On the continuity of the multivariate Pade operator, J. Comput. Appl. Math. 11 (1984), 95-102.

[76] J. Della Dora, Contribution à l'approximation de fonctions de la variable complexe au sens de Hermite-Padé et de Hardy, Thesis, Univ. Scientifique et Médicale de Grenoble 1980.

[77] -, Quelques résultats sur la structure des tables de Padé-Hermite, in Padé Approximation and Its Applications, Amsterdam 1980, M. G. de Bruin and H. van Rossum, Eds., Lecture Notes in Math. 888, Springer, Berlin 1981, 173-185.

[78] -, Padé-Hermite approximants, in Numerical Methods in the Study of Critical Phenomena, J. Della Dora, J. Demongeol and B. Lacolle, Eds., Springer, Berlin 1981, 3-11.

[79] J. Della Dora, C. Di-Crescenzo, Approximation de Padé-Hermite, in Padé Approximation and Its Applications, Antwerp 1979, L. Wu ytack, Ed., Lecture Notes in Math. 765, Springer, Berlin 1979, 88-115.

[80] -, -, Approximants de Padé-Hermite I (Theorie), II (Programmation), Numer. Math. 43 (1984) 23-39, 41-57.

[81] E. Dubois, Algorithme de Jacobi-Perron dans un corps de séries formelles, Thèse de 3-ième cycle, Faculté des Sciences, Univ. de Caen, Caen 1970.

[82] A. Edrei, Proof of a conjecture of Schoenberg on the yenerating function of a totally positive sequence, Canad. J. Math. 5 (1953), 86-94.

[83] H. R. P. Ferguson, R. W. Forcade, Generalization of the Euclidean algorithm for real numbers to all dimensions higher than two, Bull. Amer. Math. Soc. (N.S.) 1 (1979), 912-914.

[84] G. Frobenius, Über Relationen zwischen Näherungsbrüchen von Potenzreihen, J. Reine Angew. Math. 90 (1881), 1-17.

[85] A. J. Goddijn, Enkele convergentie-eigenschappen van twee meerdimensionale Padé tafels, Dept. of Math., Univ. of Amsterdam, (in Dutch) handwritten manuscript, 1972.

[86] A. A. Gonchar, G. L. Lopez (А. А. Гончар, Г. Л. Л опсс), O mеореме Маркова длл мнозоточечных аппроксимачий Паде, Мат. Сб. 105 (147), 512-524 (1978) (= On Markov's theorem for multipoint Padé approximation, Math. USSR-Sb. 34 (1987), 449-459).

[87] A. A. Gonchar, Ye. A. Rakhmanov (A. A. Гончар, E. A. Paхманов), O сходимосmu 
совместных аппроксимачий Паде для систем функиий марковсного типа, Труды Матем. Ин-та им. В. А. Стеклова АН СССР 157 (1981), 31-48 (= On convergence of simultaneous Padé approximants for systems of functions of Markov type, Proc. Steklov. Inst. Math., Issue 3 (1983), 31-50).

[88] P. R. Graves-Morris, Generalisation of the theorem of de Montessus using Canterbury approximants, in Padé and Rational Approximation, E. B. Saff and R. S. Varga, Eds., Acad. Press, New York 1977, 73-82.

[89] -, Vector valued rational interpolants I, Numer. Math. 42 (1983), 331-348.

[90] -, Vector valued rational interpolants II, IMA J. Numer. Anal. 4 (1984), 209-224.

[91] P. R. Graves-Morris, R. Hughes Jones, G. J. Makinson, The calculation of some rational approximants in two variables, J. Inst. Math. Appl. 13 (1974), 311-320.

[92] P. R. Graves-Morris, C. D. Jenkins, Generalised inverse vector valued rational interpolation, in Padé Approximation and Its Applications, Bad Honnef 1983, H. Werner and H.-J. Bünger, Eds., Lecture Notes in Math. 1071, Springer, Berlin 1984, 144-156.

[93] -, -, Vector valued rational interpolants III, Constr. Approx. 2 (1986), 263-289.

[94] P. R. Graves-Morris, E. B. Saff, Vector valued rational interpolants, in Rational Approximation and Interpolation, P. R. Graves-Morr is, E. B. S a ff and R. S. Varga, Eds., Lecture Notes in Math. 1105, Springer, New York 1984, 227-242.

[95] P. R. Graves-Morris, J. M. Wilkins, A fast algorithm to slove Kalman's partial realisation problem for single-input, multi-output systems, School of Mathematics, Univ. of Bradford, Report NA 87-4 (1987).

[96] R. Güting, Zur Verallgemeinerung des Kettenbruch Algorithmus I, J. Reine Angew. Math. 278/279 (1975), 165-173.

[97] -, Zur Verallgemeinerung des Kettenbruch Algorithmus I, J. Reine Angew. Math. 281 (1976), 184-198.

[98] -, Zur Verallgemeinerung des Kettenbruch Algorithmus III, J. Reine Angew. Math. 283/284 (1976), 384-387.

[99] M. Hallin, Nonstationary moving average processes, Inst. de Statistique, Univ. Libre de Bruxelles, preprint.

[100] -, Nonstationary first-order moving average processes: the model building problem, in Time Series Analysis, O. D. Anders on and M. R. Perryman, Eds., North-Holland, Amsterdam 1981, 189-206.

[101] -, Nonstationary second-order moving average processes, in Time Series Analysis, O. D. Anderson and M. R. Perryman, Eds., North-Holland, Amsterdam, 1982.

[102] -, Moving average models for time dependent autocovariance functions, Inst. de Statistique, Univ. Libre de Bruxelles, preprint.

[103] Ch. Hermite, Sur la Sonction exponentielle, C. R. Acad. Sci. LXXVI1 (1873), 18-24, 74-79, 226-233, 285-293 = Oeuvres, t. III (1873), 150-181.

[104] -, Sur la généralisation des fractions continues algébriques, Extrait d'une lettre à $M$. Pincherle, Ann. Mat. 2-ième série, XXI (1893), 289--308 = Oeuvres, t. IV (1893), 357-377.

[105] R. Hugh Jones, G. J. Makinson, The generation of Chisholm rational polynomial approximants to power series in two variables, J. Inst. Maths. Applics. 13 (1974), 299-310.

[106] A. Ја. Khinchin (А. Я. Хинчин), Lепиые дроби, 4 изд., М.-Л. (1978) (=Continued fractions, Noordhoff (Groningen, 1963) or Univ, of Chicago Press, Chicago 1964).

[107] J. van Iseghem, Convergence and divergence of columns of vector Padé approximants associated to meromorphic functions, Univ. des Sciences et Techn. de Lille Flandres-Artois, preprint.

[108] - Vector Padé Approximants, in Numerical Mathematics and Applications, R. Vich nevetsky and J. Vignes, Eds., North-Holland, Amsterdam 1986, 73-77.

[109] - Convergence of the vector $Q D$ algorithm, zeros of vector orthogonal polynomials, Univ. des Sciences et Techn. de Lille Flandres-Artois, report ANO-169, Lille 1986. 
[110] -, An extended cross-rule for vector Padé approximants, Appl. Numer. Math. 2 (1986), 143-155.

[111] -, Vector orthogonal relations. Vector $Q D$ algorithm, J. Comput. Appl. Math. 19 (1987), 141-150.

[112] -, Approximants de Padé vectoriels, Thesis, Univ. des Sciences et Techn. de Lille Flandres-Artois, Lille 1987.

[113] A. Iserles, S. P. Nørsett, Bi-orthogonal polynomials, Univ. of Cambridge, Dept. of Appl. Math. and Theor. Phys., report DAMTP 1984/NA 7, 1984.

[114] -, -, Two-step methods and bi-orthogonality, Univ. of Cambridge, Dept. of Appl. Math. and Theor. Phys., report DAMTP 1984/NA 10, 1984.

[115] -, -, Bi-orthogonality and zeros of transferred polynomials, J. Comput. Appl. Math. 19 (1987), 39-45.

[116] A. Iserles, E. B. Saff, Bi-orthogonality in rational approximation, J. Comput. Appl. Math. 19 (1987), 47-54.

[117] C. G. J. Jacobi, Allgemeine Theorie der Kettenbruchähnliche Algorithmen in welchen jede Zahl aus drei Vorhergehenden gebildet wird, J. Reine Angew. Math. 69 (1868), 29-64.

[118] L. Jacobsen, Uniform convergence of limitperiodic generalized continued fractions, Dept. of Math., Univ. of Trondheim, preprint 1987.

[119] H. Jager, A multidimensional generalisation of the Padé table, Proc. Kon. Akad. v. Wet. A'dam Ser. A67 = Indag. Math. 26 (1964), 192-249.

[120] G. John, C. H. Lutterodt, $A$ general method of calculating rational approximants in two variables, Univ. of Birmingham, preprint, Birmingham 1973.

[121] W. B. Jones, W. J. Thron, Continued Fractions: Analytic Theory and Applications, Encycl. of Math. and its Applics., vol. 11, Addison-Wesley, London 1980.

[122] G. S. Joyce, A. J. Guttman, $A$ new method in series analysis, in Padé Approximants and their Applications, Kent 1972, P. R. Graves-Morris, Ed., Acad. Press, London 1973, $163-168$.

[123] W. Jurkat, W. Kratz, A. Peyerimhoff, On best two-dimensional Dirichlet approximations and their algorithmic calculation, Math. Ann. 244 (1979), 1-32.

[124] V. A. Kalyagin (В. А. Калягин), Об одном классе полиномов, определяемых двумя соотночениями ортогональности, Мат. Сб. 110 (152), (1979) 609-627 (= On a class of polynomials defined by two orthogonality relations, Math. USSR-Sb. 38 (1981), 563-580).

[125] -, Замечание о структуре табличы Паде, Вестник Моск. ун-та матсм. мсхан. (5) 1980, 38-41 (= A note on the structure of Padé's tables, Moscow Univ. Math. Bull. 35 (5) (1980), 47-51).

[126] J. Karlss on, H. Wallin, Rational approximation by an interpolation procedure in several variables, in Padé and Rational Approximation, E. B. Saff and R. S. Varga, Eds., Acad. Press, New York 1977, 83-100.

[127] Kh. I. Kuchminskaya (Х. И. Кучминская), see the references in 181.

[128] -, On approximation of functions by two-dimensional continued fractions, in Rational Approximation and Its Application in Mathematics and Physics, Lañcut 1985, J. Gilewicz, M. Pindor and W. Siemaszko, Eds., Lecture Notes in Math. 1237, Springer, Berlin 1987, 207-216.

[129] Kh. I. Kuchminska ya, W. Siemaszk o, Rational approximation of functions by branclied continued fractions, in Rational Approximation and Is Application in Mathematics and Physics, Lańcut 1985, J. Gilewicz, M. Pindor and W. Siemaszko, Eds., Lecture Notes in Math. 1237, Springer, Berlin 1987, 24-40.

[130] D. Levin, General order Padé type rational approximants defined from double power series, Internat. J. Computer Math. 3 (1973), 371-388.

[131] P. Levrie, Pringsheim's theorem for generalized continued fractions, J. Comput. Appl. Math. 14 (1986), 439-445.

6 - Banach Center t. 24 
[132] G. L. Lopez (Л. Лопес, Гиермо) $O$ сходимости многоточечных аппроксимачий Паде длл Фуикиии стильтьесовского типа, Докл. АН СССР 239 (1978), 793-796 (= On the convergence of multipoint Padé approximants for funcrions of Stieltjes type, Soviet Math. Dokl. 19 (1978), 425-428).

[133] -, Условия сходимости многоточечных аппроксимаиий Паде для функии стильтьесовского muna, Мат. Сб. 107 (149), 69-83 (1978) (=Conditions for convergence of multipoint Pade approximants for functions of Stieltjes type, Math. USSR-Sb. 35, no. 3 (1979), 363-376).

[134] .-, Sobre la convergencia de los approximantes multipuntuales de Padé para funciones de tipo Markov, Rev. Ciencias Matemáticas 1 (1980).

[135] -, Sobre la convergencia de los approximantes multipuntuales de Padé para funciones de tipo Stieltjes, Rev. Ciencias Matemáticas 2 (1980), 43-65.

[136] -, O сходимости миоготочечных аппроксимачий Паде для мероморфных функиии cтusьmьесовского muna, Мат. Сб. 111 (153) (1980), 308-316 (= On the convergence of the Padé approximants for meromorphic functions of Stieltjes type, Math. USSR-Sb. 39, no. 2 (1981), 281-288).

[137] J. H. Loxton, A. J. van der Poorten, A note on simultaneous polynomial approximation of exponential functions, Bull. Austral. Math. Soc. 11 (1974), 333--338.

[138] -, -, Multi-dimensional generalizations of the Padé table, Rocky Mountain J. Math. 9 (1979), 385-393.

[139] C. H. Lutterodt, $A$ two dimensional analogue of Pade approximant theory, J. Phys. A 7 (1974), 1027-1037.

[140] -, Rational approximants to holomorphic functions in $n$ dimensions, J. Math. Anal. Appl. 53 (1976), 89-98.

[141] A. Magnus, Fractions continues généralisées: théorie et applications, Thesis, Univ. Catholique de Louvain, Louvain 1976.

[142] -, Fractions continues généralisées et matrices infinies, report 101, Inst. de Math. UCL, Louvain-La-Neuve 1977.

[143] -, Fractions continues généralisées et matrices infinies, Bull. Soc. Math. Belg., Sér. B 29 (1977), 145-159.

[144] K. Mahler, Ein Beweis des Thue-Siegelschen Satzes über die Approxination algebraischer Zahlen für binomischen Gleichungen, Math. Ann. 105 (1931), 267-276.

[145] -, Zur Approximation der Exponentialfunktion und des Logarithmus I, II, J. Reine Angew. Math. 166 (1932), 118-150.

[146] -, Applications of some formulae by Hermite to the approximation of exponentials and logarithms, Math. Ann. 168 (1967), 200-227.

[147] -, Perfect systems, Compositio Math. 19 (1968), 95-166.

[148] J. Mall, Grundlagen für eine Theorie der mehrdimensionalen Padéschen Tafel, Inaugural Dissertation, München 1934.

[149] R. de Montessus de Ballore, Sur les fractions continues algébriques, Bull. Soc. Math. France 30 (1902), 26-32.

[150] J. A. Murphy, M. R. O'D on ohue. A two-variable generalization of the Stieltjes-type continued fraction, J. Comput. Appl. Malh. 4 (1978), 181-190.

[151] Je. M. Nikishin (Е. M. Ни кишин), O совмеспнысх аппроксимациях Паdе, Мат. С.б. 113 (155), (1979), 60-63 (= On simultaneous Padé approximants, Math. USSR-Sb. 41 (4) (1982), 409 425).

[152] -, O системе марковских фуикиий, Вестник Моск. ун.-та. матем. механ. (4) (1979), 60-63 (= A system of Markov functions, Moscow Univ. Math. Bull. 34 (4) (1979), 63-66).

[153] J. Null all, The convergence of Padé approximants and their generalisations, in The Riemann Problem, Complete Integrability and Arthimetic Applications IHES/Columbia University 1979-1980, D. V. Chudnovsky and G. V. Chudnovsky, Eds. Lecture Notes in Math. 925, Springer, New York 1982, 246-257. 
[154] J. Nuttal, Asymptotics of diagonal Hermite-Padé approximants, J. Approx. Theory 42 (1984), 299-386.

[155] J. Nuttall, G. M. Troja n, Asymptotics of Hermite-Padé approximants for a set of functions with different branch points, Constr. Approx. 3 (1987), 13-29.

[156] H. Padé, Sur la représentation approchée d'une fonction par des fractions rationnelles, Ann. Sci. École Norm. Sup. (3) 9, supplément (1892), 1-93.

[157] - Sur la généralisalion des fractions continues algébriques, C. R. Hebd. Acad. France à Paris 118 (1894), 848-850.

[158] -, Sur la généralisation des fractions continues algébriques, J. Math. Pures Appl. (4) X (1894), 291-329.

[159] - Mémoire sur les développements en fractions continues de la fonction exponentielle pouvant servir d'introduction à la théorie des fractions continues algébriques, Ann. Sci. École Norm. Sup. (3) 16 (1899), 395-426.

[160] V. I. Parusnikov (В. И. Парусников), Алгоритм Якоби-Перрона и совместне приближение функицй, Мат. Сб. 114 (156), (1982), 322-333 (= The Jacobi-Perron algorithm and simultaneous approximation, Math. USSR-Sb. 42 (1982), 287-296).

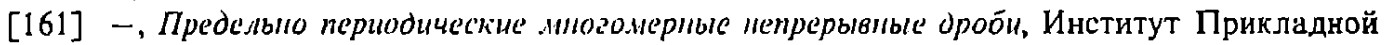
Матсматики им. М. В. Келдыша АН СССР, препринт 62, Москва 1983.

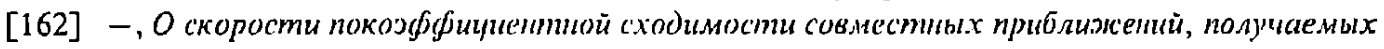
по алгоритму Якоби-Перрона, Сибирский Мат. журнал (6) (1984), 128-135 (= Соеfficientwise convergence rate of approximations obtained by Jacobi-Perron algorit/m, Siberian Math. J. 25, 2 (1985), 935-941).

[163] -, Слабосовершенные системы буикиий и многомерные пепрерьвные дроби, Весткик Моск. ун-та матем. механ. (2) (1984), 13-17 (= Weakly perfect systems and multidimensional continued fractions, Moscow Univ. Math. Bull. 39 (2) (1984), 16-21).

[164] - On the convergence of the multidimensional limit-periodic contimed fractions, in Rational Approximaton and Its Application in Mathematics and Physics, Lenicul 1985, J. Gilewicz, M. Pindor and W. Siemaszko, Eds. Lecture Notes in Math. 1237, Springer, Berlin 1987. 217-227.

[165] R. Paysant-Le Roux, E. Dubois, Algorithme de Jacobi-Perron dans un corps de séries formelles, C. R. Acad. Sci. Paris Sér. l Math. 272 (1971), 564-566.

[166] O. Perron, Grundlagen für eine Theorie des Jacobischen Kettenbruchalgorithmus, Math. Ann. 64 (1907), 1-76.

[167] -, Die Lehre von den Kettenbrüchen II, BG Teubner Verlag, Stuttgart 1957.

[168] S. Pincherle, Di un'estensione dell'algoritmo delle frazioni. Rend. Reale Inst. Lombardo Sci. Lett. (Milano) 22 (1889), 355-558.

[169] N. Pipping, see the relerences in $21,22$.

[170] A. J. van der Poorten, Simultaneous algebraic approximation of functions, Thesis, The Univ. of New South Wales, 1968.

[171] -, Perfect approximation of functions, Bull. Austral. Math. Soc. 5 (1971) 117-126.

[172] A. Pringsheim, Über Konvergenz und funktionentheoret ischen Charakter gewisser limitärperiodischer Kellenbrüchen, Bayer. Akad. Wiss. Math. Naturw. KI. Sitz.-Berichte 40 (1910), 6. Abh. $1-52$.

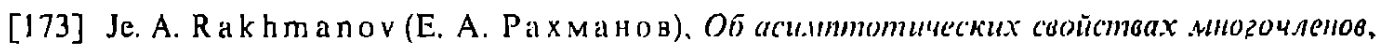

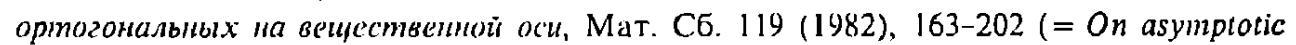
properties of polynomials which are orthogomal on the real axis, Mat. Sb. 119 (1982), 163-202).

[174] D. E. Roberts, P. R. Graves-Morris, The application of generalised inverse rational interpolants in the modal analysis of vibrating structures $I$, preprint.

[175] H. Rütishauser, Über cine Verallgemeinerung der Ketlenbrüche, Z. Angew. Math. Mech. 39 (1958), 278-279.

[176] P. Sablonniere, Padé-type approximants for mullivariate series of functions, in Padé 
Approximation and Its Applications, Bad Honnef 1983, H. Werner and H.-J. Bünger, Eds.. Lecture Notes in Math. 1071, Springer, Berlin 1984, 238-251.

[177] I. J. Schoen berg, Some analytic aspects of the problem of smoothing, in Studies and Essays presented to R. Courant on His 60th Birthday, Jan. 8, 1948, Wiley, New York 1948, 331-370.

[178] F. Sch weiger, The metrical theory of the Jacobi-Perron algorithm, Lecture Notes in Math. 334, Springer, Berlin 1973.

[179] E. S. Selmer, Om flerdimensjonal kjedebrok, Nord. Mat. Tidskr. 9 (1961), 37-43.

[180] R. E. Shafer, On quadratic approximation, SIAM J. Numer. Anal. 111 (1974), 447-460.

[181] V. Ja. Skorobogatko (B. Я. Скоробогатко), Теория ветөящихся цепных дробей и её применение в өынислительной математике, Москва 1983.

[182] -, Branched continued fractions and convergence acceleration problems, in Rational Approximaton and Its Application in Mathematics and Physics, Lañcut 1985, J. Gilewicz, M. Pindor and W. Siemaszk o, Eds., Lecture Notes in Math. 1237, Springer, Berlin 1987, 46-50.

[183] V. N. Sorokin (B. Н. Сороки и), Асимптотика линейных функчиональльгх форм для одиого класса Марковских функций, Деп. 4526-82, 16 ангуста 1982 г., ВИНИТИ AH CCCP.

[184] -, Асимптотика линейных функинопалыьых форм от двух логарифмов, УМН 38 (1) (1983), 193-194.

[185] -, О совместном приблимении нескольких линейных форм, Вестник Моск. ун-та. матем. механ. (1) (1983), 44-47 (= Simultaneous approximation of several linear forms, Moscow Univ. Math. Bull. 38 (1983), 53-56.)

[186] -, Обобщение классических ортогональных многочленов и сходимость совместных аппроксимачий Паде, Тр. Сем. им. И. Г. Петровского, вып. 11, Изд-во Моск. ун-та, Москва 1986, 125-165.

[187] H.Stahl, Asymptotics of Hermite-Padé polynomials and related approximants - A summary of results, preprint TFH, Berlin 1987.

[188] -, On the convergence of generalized Padé approximants, Constr. Approx. 5 (1989), 221-240.

[189] -, Asymptotics of Hermite-Padé polynomials and related approximants - A summary of results, in Nonlinear Numerical Methods and Rational Approximation, A. Cuyt, Ed., D. Reidel, Dordrecht 1988, 23-53.

[190] G. Szekeres, Multidimensional continued fractions, Ann. Univ. Sci. Budapest Eötvös Sect. Math. 13 (1970), 113-140.

[191] E. B. van Vleck, On the convergence of continued fractions with complex elements, Trans. Amer. Math. Soc. 2 (1901), 476-483.

[192] G. F. Voronoi, On a generalization of the algorithm of continued fractions, Thesis (in Russian), Warszawa 1896.

[193] H. S. Wall, Analytic Theory of Continued Fractions, Chelsea, New York 1973.

[194] H. Werner, Multivariate Padé approximation, Numer. Math. 48 (1986), 429.440.

[195] -, On the continuity properties of the multivariate Padé operator $T_{m, n}$, in Rational Approximation and Its Application in Mathematics and Physics, Lańcut 1985, J. Gilewicz, M. Pindor and W. Siemas sk o, Eds., Lecture Notes in Math. 1237, Springer, Berlin 1987, 125-133.

Presented to the Semester

Numerical Analysis and Mathematical Modelling

February 25-May 29, 1987 